\title{
Single-particle characterization of ice-nucleating particles and ice particle residuals sampled by three different techniques
}

\author{
A. Worringen ${ }^{1,7}$, K. Kandler ${ }^{1}$, N. Benker ${ }^{1}$, T. Dirsch ${ }^{1}$, S. Mertes $^{2}$, L. Schenk ${ }^{2}$, U. Kästner ${ }^{2}$, F. Frank ${ }^{3}$, B. Nillius ${ }^{3, *}$, \\ U. Bundke $^{3, * *}$, D. Rose $^{3}$, J. Curtius ${ }^{3}$, P. Kupiszewski ${ }^{4}$, E. Weingartner ${ }^{4, * *}$, P. Vochezer ${ }^{5}$, J. Schneider ${ }^{6}$, S. Schmidt ${ }^{6}$, \\ S. Weinbruch ${ }^{1}$, and M. Ebert ${ }^{1}$ \\ ${ }^{1}$ Institut für Angewandte Geowissenschaften, Technische Universität Darmstadt, Schnittspahnstr. 9, \\ 64287 Darmstadt, Germany \\ ${ }^{2}$ Leibniz-Institut für Troposphärenforschung, Permoserstraße 15, 04318 Leipzig, Germany \\ ${ }^{3}$ Institut für Atmosphäre und Umwelt, Goethe-Universität Frankfurt am Main, Altenhöferallee 1, \\ 60438 Frankfurt am Main, Germany \\ ${ }^{4}$ Laboratory of Atmospheric Chemistry, Paul Scherrer Institute, 5232 Villigen PSI, Switzerland \\ ${ }^{5}$ Institute for Meteorology and Climate Research, Karlsruhe Institute of Technology, P.O. Box 3640, \\ 76021 Karlsruhe, Germany \\ ${ }^{6}$ Max-Planck-Institut für Chemie, Hahn-Meitner-Weg 1, 55128 Mainz, Germany \\ ${ }^{7}$ Institut für Physik der Atmosphäre, Johannes Gutenberg Universität Mainz, 55099 Mainz, Germany \\ *now at: Max-Planck-Institute für Chemie, Hahn-Meitner-Weg 1, 55128 Mainz, Germany \\ ** now at: Forschungszentrum Juelich GmbH, 52425 Juelich, Germany \\ *** now at: University of Applied Sciences and Arts Northwestern Switzerland, School of Engineering, \\ Institute of Aerosol and Sensor Technology, Klosterzelgstrasse 2, 5210 Windisch, Switzerland
}

Correspondence to: S. Weinbruch (weinbruch@geo.tu-darmstadt.de)

Received: 14 August 2014 - Published in Atmos. Chem. Phys. Discuss.: 8 September 2014

Revised: 20 February 2015 - Accepted: 17 March 2015 - Published: 22 April 2015

\begin{abstract}
In the present work, three different techniques to separate ice-nucleating particles (INPs) as well as ice particle residuals (IPRs) from non-ice-active particles are compared. The Ice Selective Inlet (ISI) and the Ice Counterflow Virtual Impactor (Ice-CVI) sample ice particles from mixed-phase clouds and allow after evaporation in the instrument for the analysis of the residuals. The Fast Ice Nucleus Chamber (FINCH) coupled with the Ice Nuclei Pumped Counterflow Virtual Impactor (IN-PCVI) provides ice-activating conditions to aerosol particles and extracts the activated particles for analysis. The instruments were run during a joint field campaign which took place in January and February 2013 at the High Alpine Research Station Jungfraujoch (Switzerland). INPs and IPRs were analyzed offline by scanning electron microscopy and energy-dispersive X-ray microanalysis to determine their size, chemical composition and mixing state. Online analysis of the size and chemical composition of INP activated in FINCH was performed by laser
\end{abstract}

ablation mass spectrometry. With all three INP/IPR separation techniques high abundances (median 20-70\%) of instrumental contamination artifacts were observed (ISI: Si-O spheres, probably calibration aerosol; Ice-CVI: Al-O particles; FINCH + IN-PCVI: steel particles). After removal of the instrumental contamination particles, silicates, Ca-rich particles, carbonaceous material and metal oxides were the major INP/IPR particle types obtained by all three techniques. In addition, considerable amounts (median abundance mostly a few percent) of soluble material (e.g., sea salt, sulfates) were observed. As these soluble particles are often not expected to act as INP/IPR, we consider them as potential measurement artifacts. Minor types of INP/IPR include soot and $\mathrm{Pb}$-bearing particles. The $\mathrm{Pb}$-bearing particles are mainly present as an internal mixture with other particle types. Most samples showed a maximum of the INP/IPR size distribution at $200-400 \mathrm{~nm}$ in geometric diameter. In a few cases, a second supermicron maximum was identified. 
Soot/carbonaceous material and metal oxides were present mainly in the sub-micrometer range. Silicates and Ca-rich particles were mainly found with diameters above $1 \mu \mathrm{m}$ (using ISI and FINCH), in contrast to the Ice-CVI which also sampled many submicron particles of both groups. Due to changing meteorological conditions, the INP/IPR composition was highly variable if different samples were compared. Thus, the observed discrepancies between the different separation techniques may partly result from the non-parallel sampling. The differences of the particle group relative number abundance as well as the mixing state of INP/IPR clearly demonstrate the need of further studies to better understand the influence of the separation techniques on the INP/IPR chemical composition. Also, it must be concluded that the abundance of contamination artifacts in the separated INP and IPR is generally large and should be corrected for, emphasizing the need for the accompanying chemical measurements. Thus, further work is needed to allow for routine operation of the three separation techniques investigated.

\section{Introduction}

The impact of clouds - and in particular cloud-aerosol interactions - on earth's radiation balance is still one of the most uncertain aspects in our understanding of the climate system (Flato et al., 2013). The understanding of tropospheric cloud ice formation processes is crucial for predicting precipitation and cloud radiative properties. Aerosol-cloud interactions play a key role in determining cloud properties like phase, size distribution and colloidal stability of the cloud elements, as well as the lifetime, dimensions and precipitating efficiency of a cloud. Though there have been advances during the last decades, in particular for aerosol-cloud interactions, the level of scientific understanding is still classified as "very low" to "low" (Flato et al., 2013). A considerable uncertainty of the response of aerosol and cloud processes to changes in aerosol properties still arises from the lack of fundamental understanding of the interaction of aerosol particles with the cloud ice phase (Lohmann and Feichter, 2005). Although large attention was given to field studies in the last decade (e.g., Richardson et al., 2007; Prenni et al., 2009a, c; Santachiara et al., 2010; Ardon-Dryer et al., 2011; Conen et al., 2012; Ardon-Dryer and Levin, 2014), these measurements cover only limited geographic regions as well as a limited time. Thus, additional field work is certainly needed.

Many ice nucleation experiments were performed under laboratory conditions (e.g., Hoose and Möhler, 2012, and references therein), and provided valuable knowledge on icenucleating particle (INP) properties of pure components and artificially generated mixtures. Mineral dust and biological particles are regarded in general as efficient INP, while experiments disagreed on the INP abilities of soot and organics (Hoose and Möhler, 2012). Sea salt and sulfate are often not considered as INP (Pruppacher and Klett, 1997). However, this conclusion is challenged by several authors (Abbatt et al., 2006; Schill and Tolbert, 2014). Furthermore, it was shown recently in laboratory work for $\mathrm{NaCl}$ particles that a partial efflorescence under suitable conditions might lead to ice activation (Wise et al., 2012). The situation is even more complex in the ambient atmosphere, where particles are often present as a complex mixture of different compounds. In addition, the particles may be modified by heterogeneous processes, which may change their ice nucleation ability. In laboratory experiments, these effects are currently addressed for single substances (Hoose and Möhler, 2012; Wex et al., 2014), but the level of atmospheric mixing complexity is not yet realized. Though mixing state was regarded by previous investigations (Knopf et al., 2010, 2014; Ebert et al., 2011; Hiranuma et al., 2013), the data basis is still sparse and further field work is needed.

During the last decade, several techniques emerged which are capable of distinguishing INPs or ice particle residuals (IPRs) for subsequent chemical analysis. Particles are usually exposed to thermodynamic conditions favoring ice nucleation, either in the airborne state or on a substrate. Examples for these techniques are the Fast Ice Nucleus Chamber (FINCH) (Bundke et al., 2008) in combination with the Ice Nuclei Pumped Counterflow Virtual Impactor (INPCVI) (Schenk et al., 2014), the Continuous Flow Diffusion Chamber (CFDC) in combination with the laboratory counterflow virtual impactor (LCVI) (Cziczo et al., 2003) and the Frankfurt Ice Nuclei Deposition Freezing Experiment (FRIDGE) (Bundke et al., 2008; Klein et al., 2010). While in FINCH + IN-PCVI and CFDC + LCVI the particles are kept airborne, ice nucleation occurs on an ice-inert substrate in FRIDGE. In contrast, analysis of IPR relies on the natural selection of INP by a cloud. While for cirrus clouds all cloud elements can be investigated (Cziczo and Froyd, 2014), for mixed-phase clouds the ice particles need to be separated from droplets. Ice particle separation can be accomplished with different techniques. In the Ice Selective Inlet (ISI; Kupiszewski et al., 2014) droplets present in the sampling flow are evaporated in an ice-saturated environment and the remaining ice crystals are subsequently separated from non-activated particles using a PCVI. Alternatively, cloud elements can be impacted on a cooled surface collecting the droplets while bouncing the ice particles for further analysis (Ice Counterflow Virtual Impactor, Ice-CVI) (Mertes et al., 2007).

In the present work, three state-of-the-art techniques for INP/IPR sampling - ISI, Ice-CVI and FINCH + IN-PCVI - were operated in a joint field experiment to sample atmospheric mixed-phase clouds and characterize the sampled INP/IPR with respect to their morphology, chemical composition, particle size and mixing state. The High Alpine Research Station Jungfraujoch (Switzerland) was chosen as field site for logistic reasons (easy access to a location with frequent presence of mixed phase clouds). In addition, as 
Table 1. Techniques and operation principles used for ice-nucleating particle (INP) and ice particle residual (IPR) differentiation.

\begin{tabular}{|c|c|c|c|c|c|c|}
\hline $\begin{array}{l}\text { INP/IPR separating } \\
\text { technique }\end{array}$ & Principle of operation & $\begin{array}{l}\text { Mode of op- } \\
\text { eration }\end{array}$ & $\begin{array}{l}\text { Ice nucle- } \\
\text { ation loca- } \\
\text { tion }\end{array}$ & $\begin{array}{l}\text { Separated } \\
\text { particle } \\
\text { type }\end{array}$ & $\begin{array}{l}\text { Freezing } \\
\text { mechanisms }\end{array}$ & $\begin{array}{l}\text { Size fraction of } \\
\text { sampled ice } \\
\text { hydrometeors }\end{array}$ \\
\hline $\begin{array}{l}\text { Fast Ice Nucleus Cham- } \\
\text { ber (FINCH) + Ice Nu- } \\
\text { clei pumped Counter- } \\
\text { flow Virtual Impactor } \\
\text { (IN-PCVI) }\end{array}$ & $\begin{array}{l}\text { activation of INPs un- } \\
\text { der suitable thermo- } \\
\text { dynamic conditions, } \\
\text { separation of INPs by } \\
\text { inertia }\end{array}$ & $\begin{array}{l}\text { in-cloud and } \\
\text { out of cloud, } \\
\text { continuous in } \\
\text { periods }\end{array}$ & instrument & INP & $\begin{array}{l}\text { deposition, } \\
\text { condensation, } \\
\text { immersion }\end{array}$ & not applicable \\
\hline $\begin{array}{l}\text { Ice Counterflow } \\
\text { Virtual Impactor } \\
\text { (Ice-CVI) }\end{array}$ & $\begin{array}{l}\text { removal of } \\
\text { supercooled droplets, } \\
\text { transmission of ice } \\
\text { particles }\end{array}$ & $\begin{array}{l}\text { in-cloud, } \\
\text { continuous }\end{array}$ & atmosphere & IPR & $\begin{array}{l}\text { deposition, } \\
\text { condensation, } \\
\text { immersion, } \\
\text { contact }\end{array}$ & $5 \mu \mathrm{m}<d<20 \mu \mathrm{m}$ \\
\hline Ice Selective Inlet (ISI) & $\begin{array}{l}\text { use of } \\
\text { Bergeron-Findeisen } \\
\text { process to evaporate } \\
\text { supercooled droplets, } \\
\text { separation of ice } \\
\text { crystals by inertia }\end{array}$ & $\begin{array}{l}\text { in-cloud, } \\
\text { continuous }\end{array}$ & atmosphere & IPR & $\begin{array}{l}\text { deposition, } \\
\text { condensation, } \\
\text { immersion, } \\
\text { contact }\end{array}$ & $4.9 \mu \mathrm{m}<d<20 \mu \mathrm{m}$ \\
\hline
\end{tabular}

INPs and IPRs were investigated recently at this location in a number of studies, a considerable data base is available for comparison. In the previous work, enrichment of mineral dust (Kamphus et al., 2010; Chou et al., 2011; Ebert et al., 2011), metal oxides (Ebert et al., 2011), Pb-containing particles (Cziczo et al., 2009b; Ebert et al., 2011) and carbonaceous material/black carbon (Cozic et al., 2008; Ebert et al., 2011) among INPs/IPRs were reported.

\section{Experimental}

In January/February 2013, a field campaign of INUIT (Ice Nuclei Research Unit) was performed at the High Alpine Research Station Jungfraujoch in Switzerland (JFJ; $3580 \mathrm{~m}$ a.s.1., $46.55^{\circ} \mathrm{N}, 7.98^{\circ} \mathrm{E}$ ). IPRs were separated from the interstitial aerosol and droplets by ISI and Ice-CVI. INPs were sampled from the total aerosol by FINCH + IN-PCVI (Table 1). INPs/IPRs were either collected by impactors and analyzed by scanning electron microscopy (SEM) and energy-dispersive X-ray microanalysis (EDX) or analyzed online by laser ablation mass spectrometry (LA-MS).

\subsection{INP/IPR sampling}

INPs and IPRs were sampled by three different techniques. INPs were detected by the FINCH + IN-PCVI (details of the experimental setup are given in Bundke et al., 2008, and Schenk et al., 2014). IPRs were collected via selective sampling of small $(<20 \mu \mathrm{m}$ aerodynamic diameter) ice crystals with Ice-CVI and ISI. Subsequent heating of the sampled ice crystals releases IPRs. The extracted IPRs were collected for SEM-EDX with a two-stage impactor system. The setup consisted of circular nozzles with 0.7 and $0.25 \mathrm{~mm}$ diameters op- erated at a flow rate of $0.45 \mathrm{~L} \mathrm{~min}^{-1}$ (volume), leading to an approximate $50 \%$ cutoff efficiency for aerodynamic diameters of 1 and $0.1 \mu \mathrm{m}$, respectively (for details on impactor dimensions see Kandler et al., 2007). Transmission electron microscopy grids (TEM grids type S162N9, Plano GmbH, Wetzlar, Germany) and polished elemental boron embedded in a conductive resin (for manufacturing see Choël et al., 2005) were used as impaction substrates for all methods. Both substrates provide a background signal with low interference with respect to the particle composition. While boron substrates yield a better detection of carbon in the particles and allow for larger particle numbers due to less substrate damage, the TEM grids in principle provide the possibility of being used in a TEM for phase analysis and easier detection of coatings.

\subsubsection{Coupling of FINCH and IN-PCVI}

FINCH + IN-PCVI was operated in clouds as well as during cloud-free periods. Aerosol particles and cloud elements were sampled from the atmosphere by a total aerosol inlet (Weingartner et al., 1999) with an aerosol flow of approximately $2.25 \mathrm{~L} \mathrm{~min}^{-1}$. The aerosol was dried by heating to evaporate the water of the hydrometeors. The dried aerosol containing all interstitial particles and cloud element residuals was then transported into FINCH, in which a supersaturation with respect to ice is achieved by mixing air flows of different temperature and humidity. INPs are activated, grow while flowing through the chamber, and are counted by a purpose-built optical particle counter (OPC; for details see Bundke et al., 2010). The OPC used in this instrument is able to distinguish between supercooled water droplets and ice crystals by analyzing the polarization ratio of the scat- 
tered circular polarized light (P44 / P11 ratio of the scattering matrix; $\mathrm{Hu}$ et al., 2003). In addition, the auto-fluorescence resulting from the excitation of the grown particles with UV light is detected, which is an indication for biological particle material.

The ice crystals are then separated by the PCVI from the non-activated particles and from the small supercooled droplets (Schenk et al., 2014). As the PCVI input flow must be identical to the FINCH output flow, the counterflow must be continuously adjusted to achieve this requirement. This adjustment leads to variable cutoff diameters between 4.5 and $8 \mu \mathrm{m}$. Finally, the sampled FINCH ice particles evaporate while they are transported in a dry particle-free air.

The freezing temperature of FINCH during the campaign was slightly varied around $-22.1{ }^{\circ} \mathrm{C}$, which matched for most of the samples the outside air temperature with less than $5^{\circ} \mathrm{C}$ difference. The saturation ratio with respect to ice was varied between 1.14 and 1.80 with a mean of 1.54 for all samples. Details on the sampling conditions are given in Table S1 in the Supplement.

\subsubsection{Ice-CVI}

From the mixed-phase clouds prevailing at JFJ, IPRs were collected by the Ice-CVI (Mertes et al., 2007). It consists of a series of different modules that allow sampling of small ice particles by a simultaneous pre-segregation of all other cloud constituents. The vertical, omnidirectional inlet already reduces the sampling of ice crystals larger than $50 \mu \mathrm{m}$, including precipitating or windblown ice particles. A virtual impactor downstream of the inlet horn limits the upper size of sampled hydrometeors to $20 \mu \mathrm{m}$. This limit is reasonable, because the collection efficiency is nearly 1 for these ice particle sizes. The ice particle breakup is minimized in the subsequent Ice-CVI components, and ice particles in this size range grow by water vapor diffusion, i.e., they should contain only the former INP as a residual particle. Downstream of the virtual impactor a pre-impactor removes supercooled drops by contact freezing on cold impaction plates. Ice particles bounce and pass the impaction plates. A conventional CVI (Mertes et al., 2005a, b) is located downstream of the pre-impactor to reject interstitial particles smaller than $5 \mu \mathrm{m}$. Thus, only ice particles in the 5-20 $\mu \mathrm{m}$ diameter range completely traverse the Ice-CVI. As with a conventional CVI these small ice crystals are injected into a particle-free and dry carrier gas which leads to evaporation and allows for the analysis of the IPR.

\subsubsection{ISI}

The novel ISI (Kupiszewski et al., 2014) was designed to extract small ice crystals from mixed-phase clouds, simultaneously counting, sizing and imaging the hydrometeors contained in the cloud with the use of WELAS 2500 sensors (Pallas GmbH, Karlsruhe, Germany) and a Particle Phase
Discriminator (PPD-2K; Kupiszewski et al., 2014). The core of the ISI is a droplet evaporation unit with ice-covered inner walls, removing droplets using the Bergeron-Findeisen process, while transmitting the ice crystals. In the final stage of the ISI, a pumped counterflow virtual impactor removes interstitials and cloud condensation nuclei released in the droplet evaporation unit from the sample flow, thus ensuring only ice crystals are transmitted. The extracted ice crystals are subsequently sublimated, releasing the IPRs which are transferred into the laboratory for further on- and offline characterization of their physical and chemical properties.

\subsection{Sample characterization}

\subsubsection{Scanning electron microscopy}

A total of 36 samples (18 from FINCH, 13 from Ice-CVI, 5 from ISI) were acquired during the field campaign. All samples were analyzed by SEM (FEI Quanta 200 FEG, FEI, Eindhoven, the Netherlands) and EDX (EDAX, Tilburg, the Netherlands). The particles of the different samples were manually characterized with respect to their chemical composition, size, morphology, internal mixing state and stability under electron bombardment. Particle size was determined as the average geometrical diameter (equivalent projected area diameter) from the electron images.

Based on chemical composition, morphology, mixing state and beam stability, 18 particle groups were defined and combined into 11 particle classes. Table 2 lists the particle groups, particle classes and classification criteria for the manual analysis.

$\mathrm{Pb}$-bearing particles were classified according to the presence of $\mathrm{Pb}$ only (i.e., as soon as $\mathrm{Pb}$ could be detected). They might be homogeneous $\mathrm{Pb}$-rich particles or particles containing $\mathrm{Pb}$-rich inclusions. In the latter case, the main matrix particles can be carbonaceous, soot, sulfate, sea salt, silicate, metal oxide, a droplet or belong to the "other" class. Droplets are identified by their typical morphology of larger residual particles centered in a halo of small residuals, originating from the splashing of the droplet at impaction. The center of the residual can consist of unstable material (e.g., sulfate) or stable sea salt, silicate, metal oxide, Ca-rich particles, or mixtures thereof. The halo particles are usually unstable under electron bombardment. Particles which could not be classified into one of the classes mentioned above are summarized in the particle class "other". This particle class contains for example $\mathrm{Zn}$-rich and $\mathrm{Mg}$-rich particles as well as $\mathrm{Sn}-$, Ba-, $\mathrm{Bi}$ - and Br-bearing particles with a total abundance of usually less than $1 \%$.

Due to the difference in sample substrate composition between TEM grids and elemental boron, in particular for the detection of carbonaceous particles and thin carbonaceous coatings, systematic deviations may occur with a potential bias towards better detection of these particles on boron. 
Table 2. Classification criteria for particle classes and particle groups. Common features for certain particle types not used for classification are given in parentheses.

\begin{tabular}{|c|c|c|c|c|c|}
\hline Class & Group & Major elements & Morphology & Mixing state ${ }^{a}$ & Beam stability \\
\hline \multirow[t]{2}{*}{ Carbonaceous ${ }^{b}$} & Carbonaceous & $\mathrm{C}$ & non-soot & no inclusion & \\
\hline & Carbonaceous + inclusion & $\mathrm{C}$ & non-soot & inclusion & \\
\hline Secondary & Secondary & $\mathrm{C}, \mathrm{O}, \mathrm{S}$ & & & \\
\hline \multirow[t]{2}{*}{ Sulfate } & Sulfate & $\mathrm{S}, \mathrm{O},(\mathrm{Na}, \mathrm{K})$ & & no residual & unstable \\
\hline & Sulfate + inclusion & $\mathrm{S}, \mathrm{O},(\mathrm{Na}, \mathrm{K})$ & & residual & unstable \\
\hline \multirow{2}{*}{ Soot } & Soot & $\mathrm{C}$ & soot-like & no coating & \\
\hline & Soot mixture & $\mathrm{C}$ & soot-like & coating & \\
\hline \multirow[t]{2}{*}{ Sea salt } & Sea salt & $\mathrm{Na}, \mathrm{Cl},(\mathrm{K}, \mathrm{Mg})$ & & no inclusion & \\
\hline & Sea salt + inclusion & $\mathrm{Na}, \mathrm{Cl},(\mathrm{K}, \mathrm{Mg})$ & & inclusion & \\
\hline \multirow[t]{2}{*}{ Ca-rich } & Ca-rich & $\mathrm{Ca}, \mathrm{O},(\mathrm{Mg}, \mathrm{S}, \mathrm{C})$ & & no inclusion & \\
\hline & Ca-rich + inclusion & $\mathrm{Ca}, \mathrm{O},(\mathrm{Mg}, \mathrm{S}, \mathrm{C})$ & & inclusion & \\
\hline \multirow[t]{2}{*}{ Metal oxide } & Metal oxide & $\mathrm{Fe}, \mathrm{Al}, \mathrm{Ti},(\mathrm{Mn})$ & & no coating & \\
\hline & Metal oxide + coating & $\mathrm{Fe}, \mathrm{Al}, \mathrm{Ti},(\mathrm{Mn})$ & & coating & \\
\hline \multirow[t]{2}{*}{ Silicate } & Silicate & $\mathrm{Si}, \mathrm{Al},(\mathrm{K}, \mathrm{Ca}, \mathrm{Mg}, \mathrm{Fe}, \mathrm{Ti})$ & & no coating & \\
\hline & Silicate mixture & $\mathrm{Si}, \mathrm{Al},(\mathrm{K}, \mathrm{Ca}, \mathrm{Mg}, \mathrm{Fe}, \mathrm{Ti})$ & & $\begin{array}{l}\text { coating or } \\
\text { agglomerates }\end{array}$ & \\
\hline Pb-bearing & Pb-bearing & $\begin{array}{l}\mathrm{Pb} \text { present (also as } \\
\text { minor component) }\end{array}$ & & & \\
\hline Droplet & Droplet & & $\begin{array}{l}\text { particle centered } \\
\text { in ring of } \\
\text { smaller particles }\end{array}$ & & \\
\hline Other & Other & & & & \\
\hline
\end{tabular}

\footnotetext{
a Based on detailed SEM observations. Inclusion refers to a small object with different chemical composition inside a particle. Residuals are compounds left after evaporation of a volatile matrix. Coating is a small film on the surface of a particle. Agglomerates are composed of distinguishable objects of similar size. ${ }^{b}$ Carbonaceous particles are interpreted as organic compounds which condensed from the gas phase due to their unspecific morphology and the absence of tracer elements for primary biological particles (i.e., N, P, K).
}

\subsubsection{Laser ablation mass spectrometry}

LA-MS was carried out with ALABAMA (Aircraft-based Laser Ablation Aerosol Mass Spectrometer), which was originally developed for aircraft operation (Brands et al., 2011) but was also used in several ground-based measurement campaigns. It provides the chemical composition of single aerosol particles in an aerodynamic particle size range between 150 and $1500 \mathrm{~nm}$, including refractory compounds such as metals, dust, and soot. It was used during the INUITJFJ campaign for the analysis of background aerosol particles and IPR (Schmidt et al., 2015). A total of 1809 IPR mass spectra were collected: 1663 with the Ice-CVI (104 operation hours) and 146 with ISI (32 operation hours).

\subsection{Statistical analysis}

Confidence intervals (after Clopper and Pearson, 1934) given in this manuscript and in the Supplement were calculated with $\mathrm{R}$ version 3.0.3 ( $\mathrm{R}$ core team, 2014). For data displayed in figures, the confidence intervals are given in the Supplement.

\subsection{Sampling location and meteorology}

The JFJ station is located in a saddle between the mountains Jungfrau and Mönch, which is oriented WSW-NNE. This topography results in a channeling of the atmospheric flow leading to a near-binary distribution of wind directions as either NW or SSE. The atmospheric conditions during the campaign are illustrated in Fig. 1. Hourly 5-day backward trajectories for the JFJ station were calculated with the HYSPLIT (Hybrid Single Particle Lagrangian Integrated Trajectory) model based on GDAS (Global Data Assimilation System) data (Draxler and Rolph, 2014).

At the top of Fig. 1, a period (labeled A) with comparatively homogeneous atmospheric conditions is marked. Trajectories for this period can be found in the Supplement (Fig. S1). It was chosen for instrumental comparison based on individual samples. Homogeneity was determined from meteorology, particle concentrations and changes in air mass origin. Period A (2 February, 13:00-18:00 UTC) can be described as follows. During the last day before arrival, air masses travel approximately along the Rhine Valley at altitudes between 1.5 and $2.5 \mathrm{~km}$. Two days before arrival, the air mass backward trajectories cross the North Sea and the United Kingdom in the same altitude range. For the rest of the trajectory length, the air masses were over the northern 

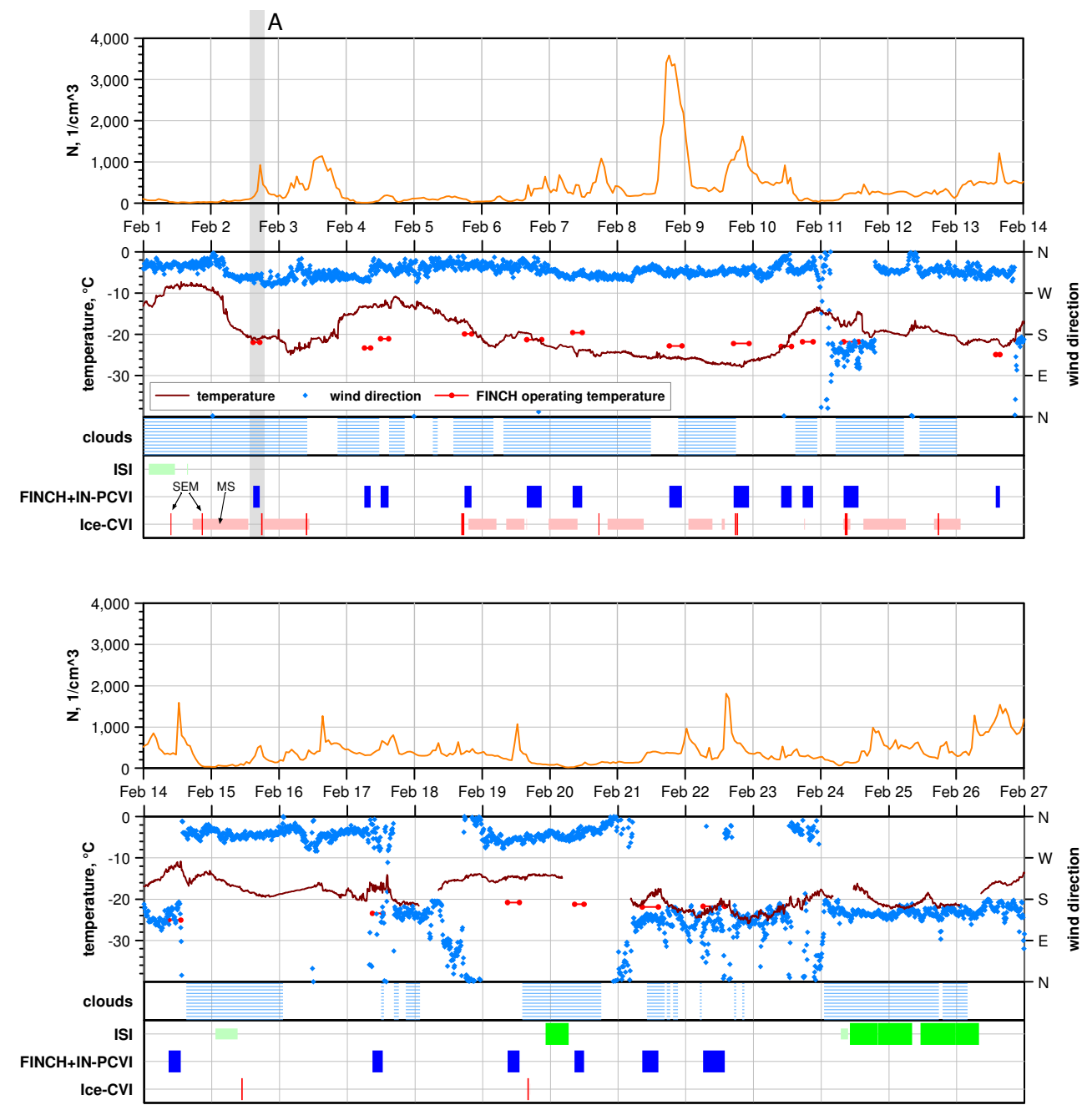

Figure 1. Atmospheric and FINCH operating conditions and INP/IPR sampling periods in February 2013. Times are given in UTC. Particle number concentrations were taken from the World Data Centre for Aerosols home page (WDCA, 2014). Temperature and wind direction were provided by the Jungfraujoch station operated by International Foundation High Altitude Research Stations Jungfraujoch and Gornergrat. Cloud presence was detected by measuring the liquid water content using a Particulate Volume Monitor (PVM-100, Gerber Scientific, Reston, VA, USA) and a Cloud Droplet Probe (Droplet Measurement Technologies, Boulder, CO, USA). Sampling phases for SEM are marked by wide, intensely colored bars; sampling phases for MS are shown as narrower, pale-colored bars. "A" marks a period used for case comparison.

Atlantic Ocean, in the region of Iceland. Wind, temperature and in-cloud conditions were very stable during this period. While the JFJ is usually in the free troposphere during the winter months (Collaud Coen et al., 2011), abrupt increases in particle concentrations may indicate a rise in the atmospheric boundary layer height to the station altitude, which leads to a local influence. This effect is visible as a sudden increase in particle concentration in the middle of this period. The samples were collected before (FINCH + IN-PCVI) and after (Ice-CVI) the highest particle concentrations, so we consider period A as of Atlantic/free-troposphere origin with minor local influence.

\section{Results}

\subsection{Contamination artifact particles from the INP/IPR sampling instruments}

The sampling instruments yielded different types of artifact particles indicated by their clear non-atmospheric origin. They consisted either of compounds used for manufacturing the instruments (e.g., aluminum, stainless steel) or had the same composition and morphology as calibration aerosol (e.g., Si-O spheres). Therefore, they were removed from further analysis. Figure 2 shows secondary electron images of the most common contamination artifact particles and their energy-dispersive X-ray spectra. The relative abundance of 

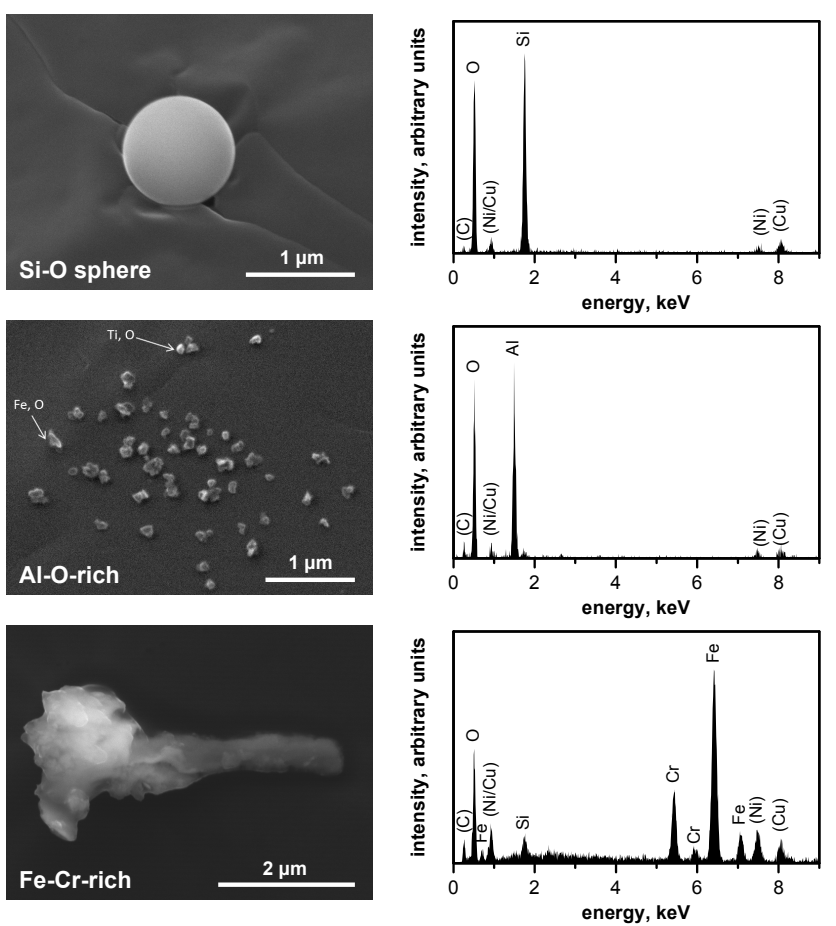

Figure 2. Secondary electron images and energy-dispersive X-ray spectra of instrumental contamination artifact particles. Characteristic X-ray peaks of elements are labeled. Elements contained in the sample substrate are given in parentheses.

the dominating artifact particles for each instrument is shown in Fig. 3 as box plots.

With all three sampling techniques, small amounts of Fe$\mathrm{Cr}$ particles are observed as an artifact. They may derive from internal abrasion of the instrument or tubing. In addition, for the samples collected on boron substrates, $\mathrm{Cu}$-rich particles are present, which are most likely fragments from the embedding material of the boron substrates (an epoxy resin containing copper chips for increased conductivity).

In the ISI samples, mainly Si-O spheres with a size of approx. $1 \mu \mathrm{m}$ are observed as artifacts. These particles were most likely introduced into the instrument during calibration of the optical particle spectrometers contained within the inlet. The abundance of $\mathrm{Si}-\mathrm{O}$ spheres in the samples ranged from 26 to $94 \%$. Including the $\mathrm{Fe}-\mathrm{Cr}$-rich and $\mathrm{Cu}$-rich artifacts, the abundance of all artifact particles ranged from 46 to $94 \%$ during the measurement period.

In the FINCH + IN-PCVI samples, $\mathrm{Fe}-\mathrm{Cr}$-rich and $\mathrm{Cu}-$ rich particles as well as a few $\mathrm{Au} / \mathrm{Ag}$ particles (not shown) are identified as instrumental artifacts. Their total abundance ranges from 0 to $60 \%$ with a median of $20 \%$.

In the Ice-CVI samples, Al-O particles - probably aluminium oxides/hydroxides - occur as artifacts. The relative abundance of these Al-O particles varied in the range of 0 $94 \%$ by number. If we consider a particle breakup during impaction as indicated by their small size in relation to the
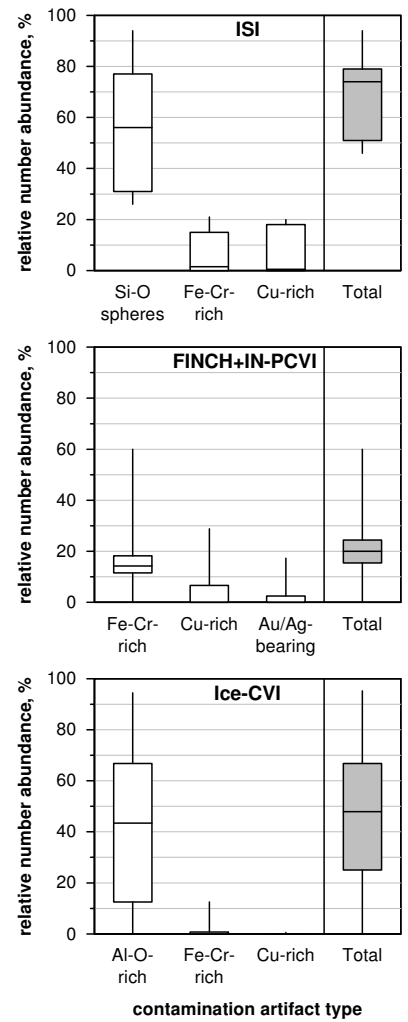

Figure 3. Box plots of the different instrumental contamination artifact particles for each sampling technique. Shown are minimum, lower quartile, median, upper quartile, and maximum.

nominal impactor cutoff size, the relative number abundance might be lower for airborne particles. As all Al-O particles are classified as artifacts in the present paper, potentially occurring atmospheric aluminium oxides/hydroxide particles in the Ice-CVI would be overlooked. However, it can be safely assumed that this potential error is minor, as no $\mathrm{Al}-\mathrm{O}$ particles with the characteristic morphology (Fig. 2) were identified with the other two sampling instruments. The abundance of other artifact particles in the Ice-CVI sample is small (range of $0-8 \%$ ).

Lead-bearing particles are frequently found in the Ice-CVI samples, but also to a much lesser extent in FINCH + INPCVI samples. These particles are regarded as effective INP in previous works (Cziczo et al., 2009b; Ebert et al., 2011). However, as parts of the Ice-CVI are manufactured from a $\mathrm{Pb}$-containing aluminum alloy, we performed additional tests to evaluate whether the $\mathrm{Pb}$-bearing particles are an instrumental contamination artifact. SEM inspection of the surface of the impaction plates revealed the presence of large, homogeneous $\mathrm{Pb}$-rich particles which consist of $\mathrm{Pb}, \mathrm{C}$ and $\mathrm{O}$ (usually without an $\mathrm{Al}$ signal, when removed from the plates). The atomic $\mathrm{Pb} / \mathrm{O}$ ratio varied between 3 and 1 , indicating a composition of partially oxidized metallic lead. No halides or sulfides could be detected on the plates. In contrast, the 
particles found as INP/IPR are mostly internally mixed with other aerosol compounds, except for a few (less than $10 \%$ ) homogeneous $\mathrm{Pb}$-rich particles with a composition similar to the $\mathrm{Pb}$ particles encountered on the impaction plates. Therefore, the latter (homogeneous $\mathrm{Pb}$ particles) are considered as artifacts. In previous campaigns at the JFJ station, $\mathrm{Pb}$-rich IPR inclusions in other particle types were identified as $\mathrm{PbS}$ (Ebert et al., 2011), indicating a non-artifact origin. This interpretation is also supported by the observed particle sizes. The $\mathrm{Pb}$-rich particles on the impaction plates are larger than $1 \mu \mathrm{m}$ (geometric diameter), in contrast to the Pb-bearing IPR which are mostly smaller than $1 \mu \mathrm{m}$. The $\mathrm{Pb}$-rich inclusions within the Pb-bearing IPR have sizes of few tens to few hundreds of nanometers. In addition, considering the low impaction speeds inside the Ice-CVI (Mertes et al., 2007), in particular, an abrasion of submicron particles can be considered as improbable. The $\mathrm{Pb}$-rich particles are predominantly observed in the Ice-CVI samples, but also to a lower extent in FINCH + IN-PCVI samples, where no Pb-containing alloys were used. This observation also indicates that the majority of $\mathrm{Pb}$-rich particles are not instrumental contamination artifacts. However, for the minor amount of large homogeneous $\mathrm{Pb}$-rich particles an instrumental source is likely.

In summary, it must be concluded that the abundance of contamination artifacts in the separated INP and IPR is generally large and cannot be neglected. Thus, the INP/IPR concentrations must be corrected to obtain accurate results. It is highly recommended that measurements of INP/IPR concentrations are always accompanied by chemical and morphological single-particle characterization in order to avoid large systematic errors caused by contamination artifacts.

\subsection{Composition of INP/IPR at the Jungfraujoch in winter}

During the field campaign 5 ISI, 18 FINCH + IN-PCVI, and 13 Ice-CVI samples were analyzed with a total (non-artifact) INP/IPR particle number of 2627. Due to the low particle number on individual samples, the INPs/IPRs from all samples were integrated for each technique (Fig. 4) to yield better statistics. Particles were classified according to their size in a sub- and supermicron range.

Silicates are the main group of INPs/IPRs, independent of sampling technique and size range (with the exception of submicron particles encountered in ISI). Ca-rich particles are predominantly found in the supermicron range with all three sampling techniques, in contrast to soot and sulfate particles, which occur mainly in the submicron range. Metal oxides are present in both size ranges with a tendency to the submicron range while sea-salt particles tend to be in the supermicron range. However, if the low number of analyzed particles and the resulting statistical uncertainty are considered, the observed differences between the techniques are regarded only as a trend. In addition, the three instruments could not be operated strictly in parallel and thus sampled different time

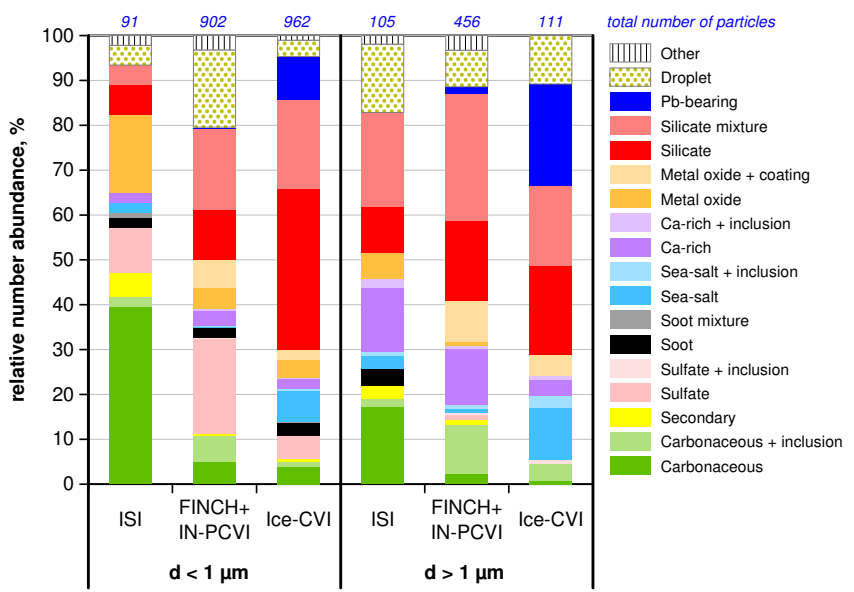

Figure 4. Relative number abundance (integrated over all samples) of different particle groups as function of sampling technique and particle size. The total number of analyzed particles is shown above the bars. For confidence intervals see Tables S2 and S3 in the Supplement.

periods. In particular, ISI samples were taken only at the end of the field campaign.

The main differences in composition trends between the three sampling methods are the high content of carbonaceous particles measured downstream of the ISI and the high content of $\mathrm{Pb}$-bearing particles obtained by Ice-CVI. The high concentration of carbonaceous particles in the ISI samples may result from different air masses being sampled at the end of the field campaign, when the ISI was operated. During this time, higher black carbon concentrations were measured than during the earlier periods (WDCA, 2014). The $\mathrm{Pb}$-bearing particles are discussed later in Sect. 3.4 in more detail.

If the 11 particle classes are grouped into four simplified components - particles of potential terrigenous origin (i.e., silicates and Ca-rich particles), C-dominated particles (carbonaceous, soot), metal-oxides-dominated and soluble particles (sulfate, droplets, sea salt) - the terrigenous particles are the main component with relative abundances of $32 \%$ (ISI), $51 \%$ (FINCH + IN-PCVI) and $55 \%$ (Ice-CVI). The C-rich particles show a higher variation due to sampling of different air masses and range from $9 \%$ (Ice-CVI), and $13 \%(\mathrm{FINCH}+\mathrm{IN}-\mathrm{PCVI})$ to $34 \%$ (ISI). The soluble particles vary between $22 \%$ (ISI and Ice-CVI) and $32 \%$ (FINCH + IN-PCVI).

The composition of the INP/IPR-samples varies between different cloud events as well as between the INP/IPR sampling techniques. The heterogeneity of the INP/IPR composition is illustrated with the example of 2 February (Fig. 5), where relatively stable atmospheric conditions prevailed. During this period, two samples were taken between 17:40-18:10 (Ice-CVI) and 14:50-17:11 UTC $(\mathrm{FINCH}+\mathrm{IN}-\mathrm{PCVI})$. The relative number abundance of the 


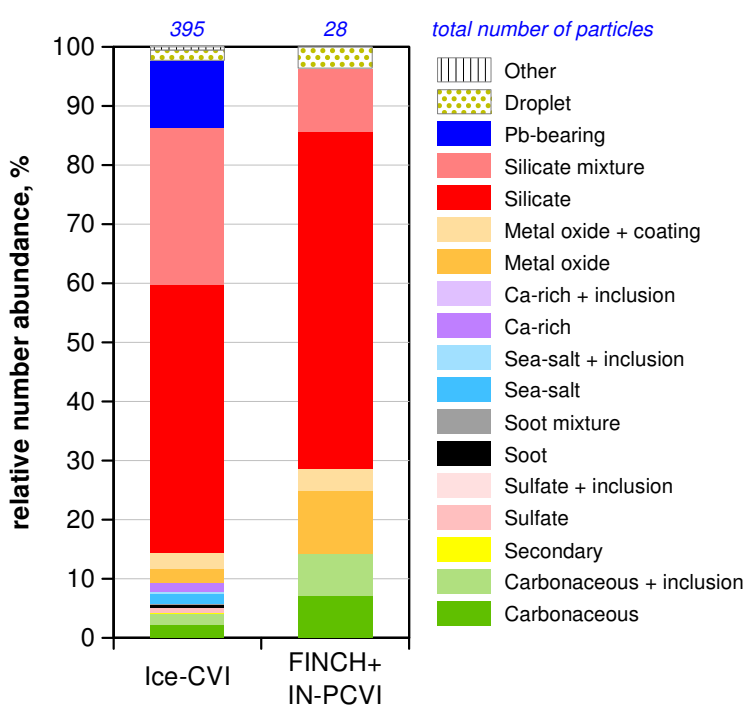

Figure 5. Relative number abundance of different particle groups among INP/IPR for 2 February determined by FINCH + IN-PCVI and Ice-CVI. The total number of analyzed particles is shown above the bars. For confidence intervals see Table S4 in the Supplement.

major components is quite similar, i.e., dominating silicates with a fraction of $71 \%$ (Ice-CVI) and $65 \%$ (FINCH + INPCVI) as well as the presence of organics and metal oxides. The relative abundance of the minor INP/IPR classes seems to differ considerably. However, due to the small number of particles sampled by FINCH + IN-PCVI, no further conclusions can be drawn. In addition, a part of these differences may be caused by the different INP/IPR sampling techniques and short-term changes in meteorological conditions.

\section{Potential INP/IPR sampling artifacts}

In addition to the clearly identifiable instrumental contamination artifacts, potential INP/IPR sampling artifacts may occur. We define potential sampling artifacts as particles, which pass the selection mechanisms similar to INPs/IPRs, while being questionable to act as INP/IPR (e.g., Pruppacher and Klett, 1997). The potential sampling artifacts include sea-salt particles, sulfate particles and particles which impact on the sampling substrates as droplets. As we cannot exclude that these particles are INPs/IPRs, we do not exclude them from further analysis in contrast to the instrumental contamination artifacts.

Droplets are characterized by their morphology of a residual with a halo (Fig. 6). While in principle the heating and drying line should lead to total evaporation of particle-bound water, obviously some particles were still in liquid state during impaction sampling. As we cannot distinguish incompletely dried IPRs from supercooled droplets, which were falsely identified as INP/IPR, we consider droplets as potential INP/IPR sampling artifacts. Sulfate particles were preferentially found in the submicron size range, while sea-salt
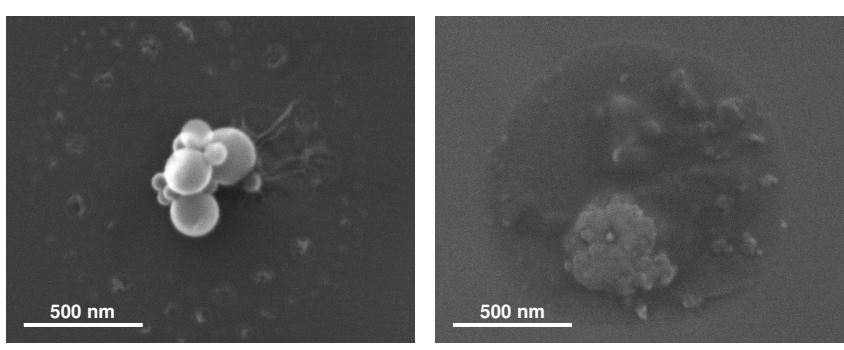

Figure 6. Secondary electron images of droplets with their typical morphology of a halo around a residual.

particles have a tendency to be of larger size. Droplets, however, occur rather uniformly in both size ranges.

The relative number abundances of the three potential sampling artifacts (droplets, (non-droplet) sulfate and sea salt) are shown as box plots (in Fig. 7), separately for each INP/IPR sampling instrument. All potential INP/IPR sampling artifacts are observed for all three techniques, and their relative abundances are on comparable levels of $0-10 \%$ for each particle type. However, the Ice-CVI, in particular, extracted a higher number of sea-salt particles as IPR. For single measurements, the abundance of these potential sampling artifacts can reach up to $40 \%$.

\subsection{Size distribution of INP/IPR components}

To allow for the display of a size distribution (Fig. 8), we combined the classes into generalized components of INP/IPR to achieve higher particle counts for each particle size interval. Instrumental contamination artifacts and $\mathrm{Pb}$ bearing particles are excluded in this presentation. Note that size distributions obtained with the different techniques cannot be compared directly due to different inlet and transmission efficiencies. However, all three methods yield a maximum of between 0.3 and $0.5 \mu \mathrm{m}$ in geometric diameter. In addition, ISI shows a secondary maximum of around $1-1.5 \mu \mathrm{m}$. With ISI and FINCH-IN-PCVI, silicates and Ca-rich particles are predominantly found at the larger particles sizes. The relative abundance of carbonaceous/soot as well as metal oxides is higher within the submicron range. The soluble and secondary particles do not show a particular size preference in their relative abundance. For the Ice-CVI, there seems to be a trend towards a higher abundance of soluble/secondary material with increasing particle size. However, this cannot be regarded as significant due to the extremely low particle numbers for supermicron particles (less than 10 for each sample and size interval). In the submicron range, no size dependency is visible.

\subsection{Mixing state and Pb-bearing INP/IPR}

A significant fraction of the INPs/IPRs consists of particles with coatings or inclusions (see groups in Fig. 4). The relative abundance of internally mixed particles for each parti- 


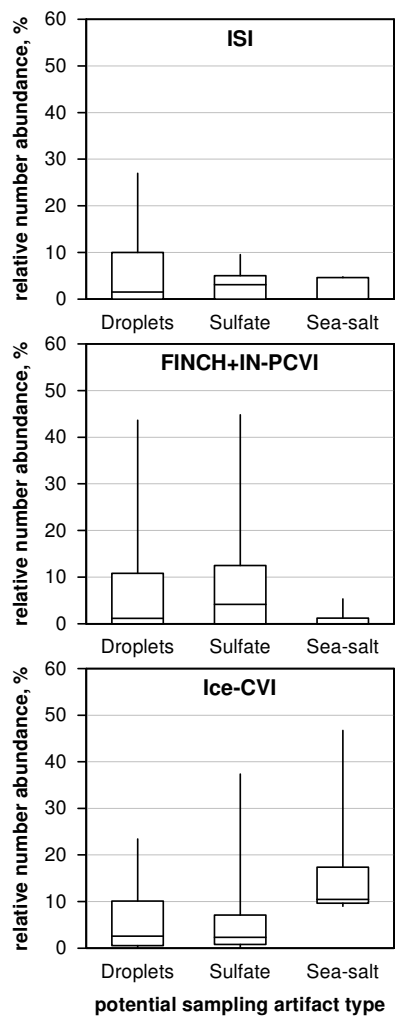

Figure 7. Box plots of impacted droplets, (non-droplet) sulfate and sea-salt abundance for ISI, FINCH + IN-PCVI and Ice-CVI. Shown are the minimum, lower quartile, median, upper quartile, and maximum.

cle type is summarized in Table 3. It is apparent that mainly silicate particles and to a lesser extent metal oxides are internally mixed. Mixing partners are mostly sulfate and carbonaceous matter, but also sea salt, if present in the total aerosol. The other particle types are less frequently internally mixed. Regarding differences between the sampling techniques, in particular INPs measured by FINCH + IN-PCVI are considerably more frequently internally mixed than IPRs of ISI and Ice-CVI. The (non-droplet) sulfates obtained as INP/IPR contain in most cases no heterogeneous inclusions. Also, most of the soot and Ca-rich particles have no coating, which is consistent for all sampling techniques. In contrast, the mixing state of carbonaceous particles was found to be highly different, rarely mixed for ISI $(7 \%)$ and frequently mixed for FINCH + IN-PCVI (64\%).

In previous IPR measurements at the JFJ station (Cziczo et al., 2009b; Ebert et al., 2011), Pb-bearing particles were found in high abundance with the Ice-CVI. For comparison with the previous work (Fig. 9), we have selected the Pbbearing particles from the total INPs/IPRs and determined their mixing partner. For comparability, the particles were classified in the same way as for the CLACE 5 campaign (Ebert et al., 2011). Pb-bearing particles are only found with Ice-CVI and FINCH + IN-PCVI. The Pb inclusions occur

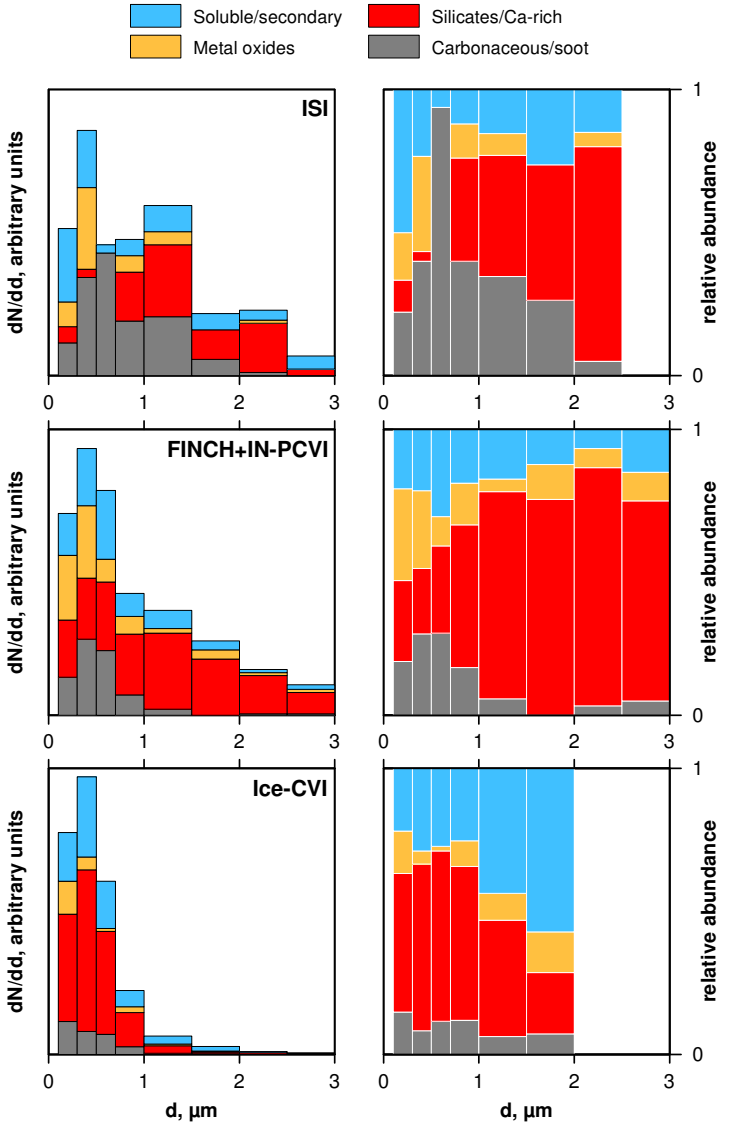

Figure 8. Average of all single sample size distributions of major INP/IPR components for ISI, FINCH + IN-PCVI and Ice-CVI. Particle groups were combined according to potential sources to obtain a sufficient number of particles in each size interval. Left column: number size distribution in $\mathrm{dN} / \mathrm{dd}$ (number density per size interval). Note that the different size distributions cannot be compared directly due to different instrumental inlet and transmission efficiencies. Right column: relative number abundance. Size intervals with less than 15 particles are not shown.

within the same main particle classes identified as INP/IPR in general, i.e., mainly silicates, Ca-rich particles, sulfates, sea-salt, and carbonaceous particles. In addition, externally mixed (homogeneous) $\mathrm{Pb}$-bearing particles are present in minor abundance. While fewer externally mixed $\mathrm{Pb}$-bearing particles were observed in the present field campaign (compared to Ebert et al., 2011), the abundance of the other Pbbearing groups is similar, except for the more abundant Alrich and the less abundant homogeneous $\mathrm{Pb}$-rich ones. 
Table 3. Number fraction (\%) of internally mixed particles in each particle class ( $95 \%$ confidence interval in parentheses).

\begin{tabular}{llll}
\hline Particle class & ISI & FINCH + IN-PCVI & Ice-CVI \\
\hline Silicate & $58.5(44.1-71.9)$ & $61.5(56.9-65.9)$ & $36.9(33.0-40.9)$ \\
Metal oxide & $4.3(0.1-21.9)$ & $66.7(58.3-74.3)$ & $38.8(27.1-51.5)$ \\
Ca-rich & $9.1(1.1-29.2)$ & $7.5(3.1-14.9)$ & $7.4(0.9-24.3)$ \\
Sea salt & $10.0(0.3-44.5)$ & $53.8(25.1-80.8)$ & $8.7(3.8-16.4)$ \\
Soot & $12.5(0.3-52.7)$ & $5.0(0.1-24.9)$ & $6.3(0.8-20.8)$ \\
Sulfate & $0.0(0.0-30.8)$ & $2.0(0.6-5.1)$ & $3.9(0.5-13.5)$ \\
Carbonaceous & $6.8(1.9-16.5)$ & $63.9(55.9-71.4)$ & $27.8(16.5-41.6)$ \\
\hline
\end{tabular}

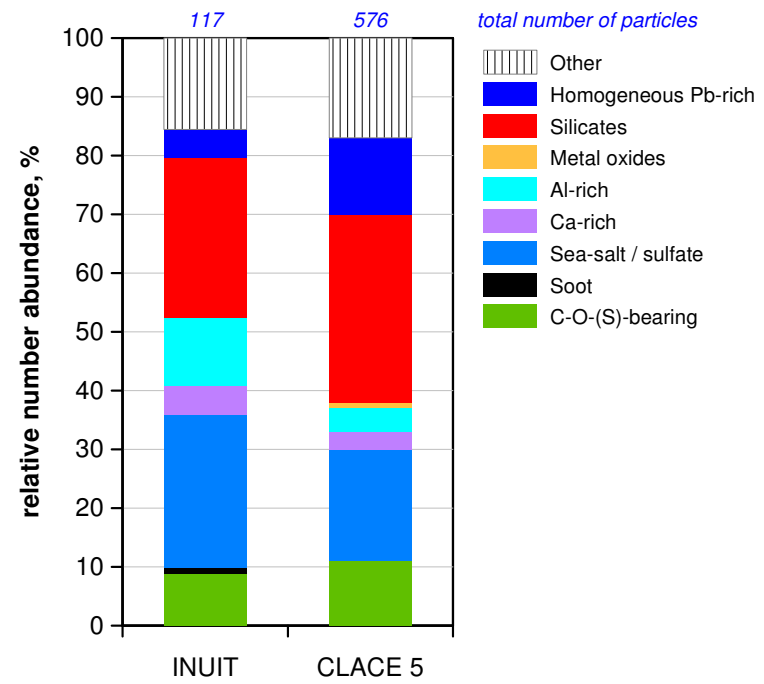

Figure 9. Comparison of the composition/mixing state of $\mathrm{Pb}$ bearing particles from INUIT (present contribution) and CLACE 5 (Ebert et al., 2011) from the Ice-CVI. Note that classification criteria and nomenclature of Ebert et al. (2011) were used for this graph. For confidence intervals see Table S5 in the Supplement.

\section{Discussion}

\subsection{Composition of INP/IPR}

\subsubsection{Which particle classes can be regarded as INP/IPR?}

Silicates were identified as common INP/IPR in laboratory experiments as well as in field experiments (Hoose and Möhler, 2012; Murray et al., 2012). Also, in our field campaign silicates are the most abundant INP/IPR components. Ca-rich particles - e.g., carbonates like calcite - are not frequently regarded as INPs (e.g., Murray et al., 2012). However, according to laboratory experiments calcite can act as an INP (Zimmermann et al., 2008). Therefore, the Ca-rich particles are regarded as INP/IPR. Metal oxides are also commonly observed as IPR in field experiments (Chen et al., 1998; DeMott et al., 2003). Similar to our study, Fe-rich particles are usually the main group within the metal oxides. In addition,
Al-, Ti-, Zn-, Cr-, and Ca-rich particles were found in the present investigation and by Chen et al. (1998).

Based on field experiments and laboratory studies, $\mathrm{Pb}$ bearing particles are in general regarded as good ice nuclei (for a detailed discussion refer to Cziczo et al., 2009b). In the present study, lead is found in two forms: as Pb-rich inclusions in other particles (major abundance) and as homogeneous $\mathrm{Pb}$-rich particles (minor abundance). The minor fraction of homogeneous $\mathrm{Pb}$-rich particles is regarded as an instrumental artifact (see discussion above), but due to its low abundance of less than $10 \%$ (equaling about 10 particles), it is neglected from further discussion.

The ice nucleation ability of soot and carbonaceous particles is discussed controversially in the previous literature. While an enrichment of black carbon in IPRs was observed in field experiments (Cozic et al., 2008), there are also other findings where organic-rich particles preferentially remain unfrozen (Cziczo et al., 2004). It has to be mentioned, however, that carbon-rich particles are often named ambiguously depending on the technique used for analysis (see also Murray et al., 2012; Petzold et al., 2013). Thus, discrepancies may arise from the fact that different types of carbonaceous material (e.g., nanocrystalline graphite, organic material) are compared. Laboratory experiments show that the ice-forming activity of soot is influenced by size, surface area and the concentration of the surface chemical groups that can form hydrogen bonds with water molecules (Gorbunov et al., 2001; Koehler et al., 2009). According to the latter, the iceforming activity of soot is close to that of metal oxides. In summary, we conclude that soot and carbonaceous particles observed in our samples were active as INP.

Also, for secondary aerosol particles the ice nucleation ability is discussed controversially. As in the case of soot and carbonaceous matter, secondary aerosol particles are found in field measurements of INP (Abbatt et al., 2006; Prenni et al., 2009b) and in laboratory experiments under cirrus cloud conditions (Hoose and Möhler, 2012). In contrast, Cziczo et al. (2004) report from a field study that organic-rich particles (internally mixed particles of sulfates and organic species) preferentially remain unfrozen. Based on our data, where secondary material is present in many INP/IPR samples, we consider these particles to be INPs/IPRs. 
Sea salt as INP/IPR was described for field studies by Cziczo and Froyd (2014) and Targino et al. (2006). While crystalline salts were found in a laboratory study to be able to act as INPs under upper-tropospheric conditions (Zuberi et al., 2001), there has been a need of clarifying the process by which a hygroscopic and soluble material should act as IN. However, recently, Wise et al. (2012) explained this behavior by fractional crystallization of the solute component under decreasing temperatures. Based on these findings, we consider sea salt as potential sampling artifacts.

Similar to sea salt, no agreement exists on the ice nucleation ability of sulfate particles. Sulfates may act as INP in cirrus clouds in the upper troposphere and lower stratosphere, both in immersion and deposition modes (Abbatt et al., 2006, and references therein; Hoose and Möhler, 2012). Sulfates acting as INP are found in a field study in increasing abundance with decreasing temperature under cirrus conditions ( -56 to $-39^{\circ} \mathrm{C}$; Twohy and Poellot, 2005) but usually not in the warmer mixed-phase clouds as encountered during our field experiment. Considering the usually high relative abundance of sulfates in the total aerosol (Ebert et al., 2011), we cannot exclude the possibility that sulfates are an artifact of the INP/IPR discrimination techniques not having perfect (i.e., $100 \%$ ) discrimination efficiency. Thus, we consider sulfate particles as potential sampling artifacts. Similar considerations apply to the observed droplets.

As explained in the methods section, contamination artifact particles were removed from the further analysis, while potential sampling artifacts are included in the data.

\subsubsection{Relative abundance of particle classes among INP/IPR}

If all INP/IPR particles of the three sampling methods are summed up, the following averaged INP/IPR composition of the whole field campaign is obtained: $52 \%$ terrigenous particles (38\% silicates, $9 \%$ metal oxides, $5 \%$ Ca-rich particles), $14 \%$ C-rich particles (12\% carbonaceous particles, $2 \%$ soot), $1 \%$ secondary particles, $11 \%$ sulfate, $11 \%$ droplets, $4 \%$ sea salt, $5 \%$ Pb-bearing particles, and $2 \%$ other particles.

A compilation of INP/IPR composition encountered in mixed-phase clouds is shown in Table 4. In general, the results of the present study are in good agreement with the findings of previous work. Silicates are the most abundant component of INP/IPR with a relative number abundance varying between 40 and $71 \%$. The second most abundant component is carbonaceous material (16-43\%), followed by salts (sea salt, sulfates, droplets) with a relative number abundance between 5 and $27 \%$. The high abundance of coated particles observed in the present study is in good agreement with Targino et al. (2006), who observed sulfur coatings for all groups indicating ageing and in-cloud processing.

An overview of IPR compositions found during 13 field campaigns of cirrus clouds is given by Cziczo and
Froyd (2014). Also, here the main particle types are mineral dust, metals, BC/soot, sea salt, sulfate, and biomass burning.

A relatively high abundance of $\mathrm{Pb}$-bearing particles, in particular internally mixed ones, seems to be characteristic for IPR at the JFJ station. They were found in previous work (Cziczo et al., 2009b; Ebert et al., 2011) and during the present field campaign. However, the fraction of $\mathrm{Pb}$ bearing particles in the whole INUIT campaign is $1 \%$ for FINCH + IN-PCVI, and $10 \%$ for Ice-CVI. In contrast, a higher fraction of up to $20 \%$ was found during CLACE 5. As helicopter flights - where $\mathrm{Pb}$-rich particles might be emitted due to leaded fuel usage - around the JFJ station were more frequent during CLACE 5 than during the present field campaign, the decrease in the abundance of $\mathrm{Pb}$-bearing particles indicates a considerable contribution of local emissions to the INP formation at the JFJ station.

Feldspar minerals and in particular K-feldspars (e.g., microcline) were discussed as efficient INPs (Atkinson et al., 2013; Yakobi-Hancock et al., 2013). Despite the fact that we did not determine the mineralogical phase of the silicate particles, we can show by SEM-EDX that they have low potassium contents $(\mathrm{K} / \mathrm{Si}$ atomic ratio $<0.1)$. Thus, it is concluded that K-feldspar particles do not occur as INP/IPR at JFJ in winter. Ca-rich particles appear in the supermicron fraction with a number abundance ratio of $0.1-0.33$ relative to silicates (depending on method and sample), which is in the range reported for natural mineral dust (Kandler et al., 2007, 2009, 2011; Coz et al., 2009). Thus, Ca-rich particles can be considered as similarly effective IN as silicates.

\subsection{Significance of mixing state and particle class for ice nucleation}

A significant fraction of the INPs/IPRs occurs as internal mixtures (Table 3). This fraction is similar to previous literature data. Chen et al. (1998) reported that a fraction of $25 \%$ of the INPs were a mixture of sulfates and elements indicative of insoluble particles. The same relative abundance of mixtures of metal oxides/dust with either carbonaceous components or salts/sulfates was reported by Prenni et al. (2009a). For the JFJ station, a slightly lower fraction of internally mixed particles was found during the CLACE 5/6 campaigns: $9-15 \%$ by Ebert et al. (2011) and up to $15 \%$ by Kamphus et al. (2010).

Especially notable is the observed difference between silicates and Ca-rich particles. While silicates are usually internally mixed, the Ca-rich particles do not have a detectable coating. This may indicate that for silicates a coating is less effective in reducing their IN ability than for Ca-rich particles, pointing to a more pronounced processing (e.g., destruction of the surface structure) of the latter. However, the influence of coatings on the ice nucleation ability of silicates is discussed controversially. In field experiments, coatings on silicates and metal oxides are commonly observed (Chen et al., 1998; Targino et al., 2006; Prenni et al., 2009a). In lab- 
Table 4. Average INP/IPR composition encountered in mixed-phase clouds for several field experiments.

\begin{tabular}{lllllll}
\hline Location & Particle type & Reference & Terrigenous $^{\mathrm{a}}$ & Carbonaceous $^{\mathrm{b}}$ & Salts $^{\text {Others }}$ \\
\hline Alaska/Arctic & INP & Prenni et al. (2009a) & $64 \%$ & $35 \%$ & IM $^{\mathrm{c}}$ & \\
Northern Scandinavia & IPR & Targino et al. (2006) & $58 \%$ & $23 \%$ & $7 \%$ & $12 \%$ \\
Jungfraujoch & IPR & Kamphus et al. (2010) & $57 \%$ & $25 \%$ & IM $^{\mathrm{c}}$ & $15 \%$ \\
Jungfraujoch & IPR & Ebert et al. (2011) & $40 \%$ & $43 \%$ & $12 \%$ & $5 \%$ \\
Jungfraujoch & INP+IPR & this study & $71 \%$ & $21 \%$ & $5 \%$ & $3 \%$ \\
Jungfraujoch & INP+IPR & this study $^{\mathrm{d}}$ & $55 \%$ & $16 \%$ & $27 \%$ & $2 \%$ \\
\hline
\end{tabular}

a Containing internal mixtures of terrigenous materials with sulfate and organics; ${ }^{\mathrm{b}}$ containing also sulfate; ${ }^{\mathrm{c}} \mathrm{IM}$ : present in internal mixtures only;

${ }^{\mathrm{d}}$ excluding droplets and sulfate; $\mathrm{Pb}$-bearing particles classified according to major particle composition; ${ }^{\mathrm{e}}$ including droplets and sulfate; $\mathrm{Pb}$-bearing particles classified according to major particle composition.

oratory experiments, conflicting results are obtained. While Cziczo et al. (2009a) as well as Hoose and Möhler (2012) reported a deactivation of the ice nuclei due to coatings, Sullivan et al. (2010) found that coatings do not always effect the ice nucleation ability. In contrast, Archuleta et al. (2005) and Zuberi et al. (2002) discuss mineral dust as an efficient nucleus for ice in $\mathrm{NH}_{4} \mathrm{SO}_{4}-\mathrm{H}_{2} \mathrm{O}$ aerosols and demonstrated that mineral particles coated with sulfate increase the freezing temperature up to $10 \mathrm{~K}$ compared to pure sulfate solutions. In addition, Richardson et al. (2007) reported that soluble coatings favor condensation-freezing nucleation and inhibit nucleation by vapor deposition. But they also mention, that coating itself may act either to increase or decrease ice nucleation efficiency independently of the nucleation mechanism.

\subsection{Comparison between FINCH + IN-PCVI, Ice-CVI and ISI}

A reasonable agreement between the different sampling techniques is obtained for the major particle classes observed among the INP/IPR. However, the variation in INP/IPR composition due to meteorological conditions in connection with the non-parallel sampling introduces a systematic error. The non-parallel sampling could not be avoided during the present field campaign, as the sampling techniques were not yet in a state allowing for synchronized operation and the available flow from the INP/IPR samplers was insufficient for a sampling for SEM and operation of LA-MS in parallel. Consequently, INP/IPR composition snapshots from different time periods needed to be integrated for comparison of the INP/IPR composition.

The reasons for the different instrumental contamination artifacts were identified. Thus, these artifacts can be avoided in future by removing their sources (e.g., replacement/sealing of contaminating surfaces, thoroughly purging). The relative abundance of potential sampling artifacts is in general low (median $<5 \%$ ), except for sea-salt particles sampled by the Ice-CVI with a median of $10 \%$ (Fig. 7).

Despite the frequent non-parallel sampling, the major INP/IPR classes found by all three techniques include sili- cates, Ca-rich particles, carbonaceous material, and metal oxides. In addition, soot was observed as a minor component in the fine fraction $(<1 \mu \mathrm{m}$ diameter $)$ by all methods. These observations are also in general agreement with previous work (see above).

In contrast, in the fine fraction a considerably higher relative abundance of carbonaceous material was found by ISI and a higher relative abundance of silicates and silicate mixtures by Ice-CVI. These differences are most likely caused by the non-parallel sampling. It must be emphasized again that samples from the ISI were only obtained during the last week of the field campaign (Fig. 1).

\subsection{Comparison between scanning electron microscopy and laser ablation mass spectrometry}

The results of the offline SEM-EDX analysis of the collected INP/IPR particles can be compared to the findings of online LA-MS. Unfortunately, both techniques could not be run in parallel because of the limited available sample flow that could be provided by the sampling systems. Due to the low INP/IPR concentrations, it was necessary to integrate all available data, which may lead to systematic errors due to significant variations in the IPR chemical composition as a function of changing air masses and meteorological conditions. Furthermore, for a comparison between SEM-EDX and LA-MS a more general particle classification scheme, combining the detailed SEM-EDX classes, was necessary.

The average particle class number abundance, derived by SEM-EDX - separately for all IPRs from the ISI and IceCVI - is compared in Fig. 10 to the results of the LAMS (Schmidt et al., 2015). The most obvious difference between the two analysis techniques is the presence of 10-18\% of secondary particles (mostly mixtures of sulfates/nitrates and/or organics), pure sulfates and droplets (residuals of volatile species like nitrates and organics) in SEM-EDX. These classes are completely absent in LA-MS. This difference can be explained by the fact that due to technical issues anions were not measured by LA-MS during the present campaign. Without the detection of anions, sulfate and nitrate cannot be identified by LA-MS, such that these particles 


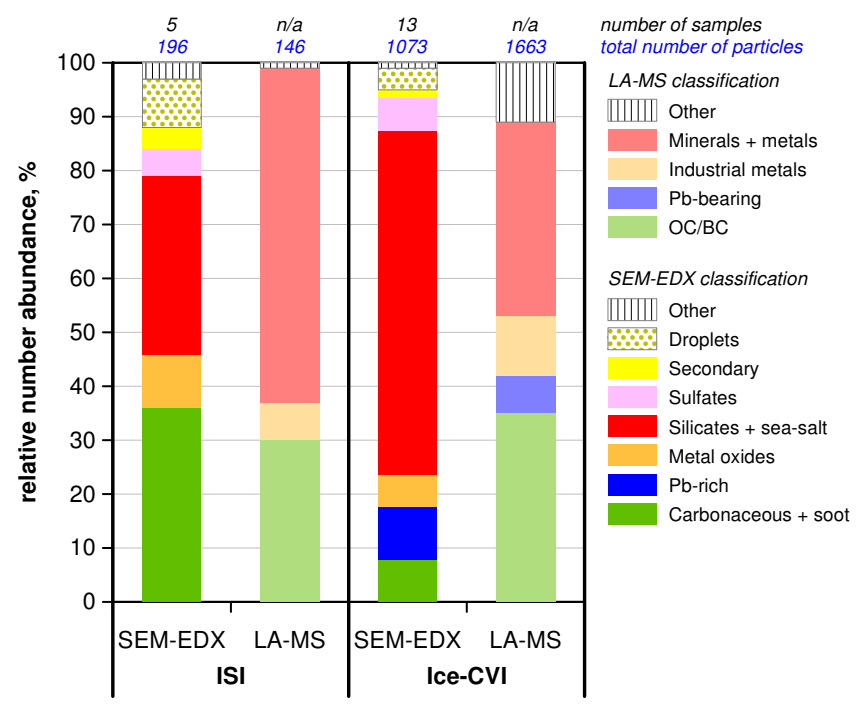

Figure 10. Comparison of particle class relative number abundance determined by SEM-EDX and LA-MS for IPRs sampled by ISI and Ice-CVI. To allow for a comparison of the two different analytical approaches of SEM-EDX and LA-MS, classes were combined accordingly. For confidence intervals see Table S6 in the Supplement.

are classified according to their dominant cations and are assigned to one of the listed particle groups.

For the other classes, a fair agreement of the results is obtained. First, the sum of mineral dust, sea salt, carbonaceous material and soot (red and green colors in Fig. 10) contributes $70-90 \%$ to the IPR. Second, metal oxides (based on SEMEDX: mainly iron oxides) occur at an abundance of 5-10\%. Third, Ice-CVI samples contain $\mathrm{Pb}$-rich particles (5-10\%), while these particles are absent in the ISI. These results do not change considerably if, for SEM-EDX, the particles outside the LA-MS size range ( $>1.5 \mu \mathrm{m}$ diameter) are neglected.

However, pronounced discrepancies exist between SEMEDX and LA-MS data, in particular for Ice-CVI. For this sampling technique, a lower abundance of carbonaceous material is found by SEM-EDX as is a higher abundance of silicates. This quantitative comparison of compositional data from both analysis techniques is hampered by the different approach in particle characterization. The particle classification with SEM-EDX relies on the characteristic X-ray signals, which can be used to quantify the chemical composition of a particle. Our classification scheme uses mainly the major elements (i.e., a relative contribution larger than 10 at. \%, excluding oxygen) detected inside a particle to assign it to the respective group. Minor elements (less than approximately 10 at. \%) are mostly neglected in particle classification. Trace elements (less than 0.5 at. \%) cannot be measured at all. In contrast, single particle LA-MS relies on ionized compounds, so ionization efficiency plays a major role. Thus, strong signals often originate from the atoms or molecules, which can be ionized best in LA-MS, but are not necessarily a major component of the particle. While LA-MS works usually well for externally mixed particles, problems can arise for the classification of internally mixed particles. In our particular case, it cannot be excluded that, for example, a silicate particle with a thin organic coating is classified as silicate in SEM-EDX (based on $\mathrm{Si}$ as major element) but as a carbonaceous particle in LA-MS (based on a strong signal of ionized carbonaceous matter). This example clearly demonstrates the need for further systematical comparison between these two analytical techniques.

\section{Summary and conclusions}

For the first time, the chemical composition of individual INPs/IPRs collected by three techniques - ISI, FINCH + INPCVI and Ice-CVI - was analyzed in a field experiment. In winter, the INP/IPR composition at the Jungfraujoch station is composed of five main classes: the dominating terrigenous silicates/Ca-rich particles, carbonaceous particles, metal oxides/hydroxides (Fe-, Ti-, or Al-oxides/hydroxides), soot, and soluble particles like sea salt, sulfates and droplets. However, the latter class of soluble particles are considered as potential sampling artifacts. Lead inclusions occur in several INPs/IPRs, while large homogeneous $\mathrm{Pb}$-rich particles are considered partially as artifacts. The composition is generally similar to earlier field experiments. Despite the nonparallel sampling, the methods roughly agree regarding major and minor components. Thus, we consider this experiment as a successful step in improving the accuracy of measuring the INP/IPR chemical composition.

For all three INP/IPR separation techniques, different contamination artifacts and potential sampling artifacts were identified. These artifacts are easily detectable by the chemical and morphological analysis. In contrast, the counting or size distribution techniques would consider these contamination and sampling artifacts as real INP/IPR and, consequently, overestimate the INP/IPR concentration. Thus, the present work provides information suitable for correction of counting techniques, for the contamination artifacts as well as for sampling artifacts. While, for the former, correction is necessary, interpretation of the latter might change with further knowledge regarding the INP/IPR abilities of soluble compounds.

Deeper data investigations reveal that beyond the agreement in the maximum of the INP/IPR size distribution, there are considerable differences between the instruments pointing to different efficiencies in INP activation and IPR separation. This is particularly obvious when we consider the large difference in internally mixed-particle abundance. While a part of these discrepancies might be explained by atmospheric variability in connection with non-parallel sampling (an issue which is expected to be overcome in future experiments by increased stability in instrument operation), they also indicate lack in understanding regarding the chem- 
ical selectivity of the different INP/IPR-discriminating techniques.

Finally, a few statements regarding limitations of the investigated techniques as well as recommendations for future work on INP/IPR can be made.

a. Measurements of INP/IPR concentrations should be always accompanied by characterization of the INP/IPR chemistry to readily identify strong contributions of instrumental artifacts. Although different techniques are in principal possible, scanning electron microscopy with high-resolution instruments has proven to be especially suited for this purpose.

b. More work is needed to clarify the ice nucleation ability of sea salt and sulfates in mixed-phase clouds.

c. More emphasis should be placed on the particle mixing state in the atmosphere. Due to its complexity, laboratory tests on the performance of the different INP/IPR sampling techniques may lead to overconfidence in the results of field measurements.

d. Substantial work is still necessary to develop the herepresented approaches of INP/IPR sampling to robust routine techniques.

\section{The Supplement related to this article is available online at doi:10.5194/acp-15-4161-2015-supplement.}

Acknowledgements. We gratefully acknowledge financial support by the Deutsche Forschungsgemeinschaft within the research group Ice Nuclei Research Unit - INUIT (FOR 1525). We thank Emanuel Hammer and Gary Lloyd for providing the liquid water content data and MeteoSwiss/EMPA for the meteorological data.

We also thank Stephan Günnel (Institut für Troposphärenforschung, Leipzig, Germany) for his help in setting up the Ice-CVI on the platform of the Sphinx Laboratory at the Jungfraujoch Research Station. In addition, we thank the International Foundation High Altitude Research Stations Jungfraujoch and Gornergrat (HFSJG) for the opportunity to perform experiments at the Jungfraujoch station.

Finally, we gratefully recognize the thorough reading and the many helpful comments of our reviewers.

Edited by: B. Ervens

\section{References}

Abbatt, J. P. D., Benz, S., Cziczo, D. J., Kanji, Z., Lohmann, U., and Möhler, O.: Solid Ammonium Sulfate Aerosols as Ice Nuclei: A Pathway for Cirrus Cloud Formation, Science, 313, 1770-1773, doi:10.1126/science.1129726, 2006.
Archuleta, C. M., DeMott, P. J., and Kreidenweis, S. M.: Ice nucleation by surrogates for atmospheric mineral dust and mineral dust/sulfate particles at cirrus temperatures, Atmos. Chem. Phys., 5, 2617-2634, doi:10.5194/acp-5-2617-2005, 2005.

Ardon-Dryer, K. and Levin, Z.: Ground-based measurements of immersion freezing in the eastern Mediterranean, Atmos. Chem. Phys., 14, 5217-5231, doi:10.5194/acp-14-5217-2014, 2014.

Ardon-Dryer, K., Levin, Z., and Lawson, R. P.: Characteristics of immersion freezing nuclei at the South Pole station in Antarctica, Atmos. Chem. Phys., 11, 4015-4024, doi:10.5194/acp-11-40152011, 2011.

Atkinson, J. D., Murray, B. J., Woodhouse, M. T., Whale, T. F., Baustian, K. J., Carslaw, K. S., Dobbie, S., O'Sullivan, D., and Malkin, T. L.: The importance of feldspar for ice nucleation by mineral dust in mixed-phase clouds, Nature, 498, 355-358, doi:10.1038/nature12278, 2013.

Brands, M., Kamphus, M., Böttger, T., Schneider, J., Drewnick, F., Roth, A., Curtius, J., Voigt, C., Borbon, A., Beekmann, M., Bourdon, A., Perrin, T., and Borrmann, S.: Characterization of a Newly Developed Aircraft-Based Laser Ablation Aerosol Mass Spectrometer (ALABAMA) and First Field Deployment in Urban Pollution Plumes over Paris During MEGAPOLI 2009, Aerosol Sci. Technol., 45, 46-64, doi:10.1080/02786826.2010.517813, 2011.

Bundke, U., Nillius, B., Jaenicke, R., Wetter, T., Klein, H., and Bingemer, H.: The fast Ice Nucleus chamber FINCH, Atmos. Res., 90, 180-186, doi:10.1016/j.atmosres.2008.02.008, 2008.

Bundke, U., Reimann, B., Nillius, B., Jaenicke, R., and Bingemer, H.: Development of a Bioaerosol single particle detector (BIO IN) for the Fast Ice Nucleus CHamber FINCH, Atmos. Meas. Tech., 3, 263-271, doi:10.5194/amt-3-263-2010, 2010.

Chen, Y., Kreidenweis, S. M., McInnes, L. M., Rogers, D. C., and DeMott, P. J.: Single particle analyses of ice nucleating aerosols in the upper troposphere and lower stratosphere, Geophys. Res. Lett., 25, 1391-1394, 1998.

Choël, M., Deboudt, K., Osán, J., Flament, P., and Van Grieken, R.: Quantitative Determination of Low-Z Elements in Single Atmospheric Particles on Boron Substrates by Automated Scanning Electron Microscopy-Energy-Dispersive X-ray Spectrometry, Anal. Chem, 77, 5686-5692, doi:10.1021/ac050739x, 2005.

Chou, C., Stetzer, O., Weingartner, E., Jurányi, Z., Kanji, Z. A., and Lohmann, U.: Ice nuclei properties within a Saharan dust event at the Jungfraujoch in the Swiss Alps, Atmos. Chem. Phys., 11, 4725-4738, doi:10.5194/acp-11-4725-2011, 2011.

Clopper, C. J. and Pearson, E. S.: The use of confidence or fiducial limits illustrated in the case of the binomial, Biometrika, 26, 404 413, doi:10.1093/biomet/26.4.404, 1934.

Collaud Coen, M., Weingartner, E., Furger, M., Nyeki, S., Prévôt, A. S. H., Steinbacher, M., and Baltensperger, U.: Aerosol climatology and planetary boundary influence at the Jungfraujoch analyzed by synoptic weather types, Atmos. Chem. Phys., 11, 5931-5944, doi:10.5194/acp-11-5931-2011, 2011.

Conen, F., Henne, S., Morris, C. E., and Alewell, C.: Atmospheric ice nucleators active $\geq-12{ }^{\circ} \mathrm{C}$ can be quantified on PM10 filters, Atmos. Meas. Tech., 5, 321-327, doi:10.5194/amt-5-321-2012, 2012.

Coz, E., Gómez-Moreno, F. J., Pujadas, M., Casuccio, G. S., Lersch, T. L., and Artínano, B.: Individual particle characteristics of 
North African dust under different long-range transport scenarios, Atmos. Environ., 43, 1850-1863, 2009.

Cozic, J., Mertes, S., Verheggen, B., Cziczo, D. J., Gallavardin, S. J., Walter, S., Baltensperger, U., and Weingartner, E.: Black carbon enrichment in atmospheric ice particle residuals observed in lower tropospheric mixed phase clouds, J. Geophys. Res., 113, D15209, doi:10.1029/2007jd009266, 2008.

Cziczo, D. J. and Froyd, K. D.: Sampling the composition of cirrus ice residuals, Atmos. Res., 142, 15-31, doi:10.1016/j.atmosres.2013.06.012, 2014.

Cziczo, D. J., DeMott, P. J., Brock, C., Hudson, P. K., Jesse, B., Kreidenweis, S. M., Prenni, A. J., Schreiner, J., Thomson, D. S., and Murphy, D. M.: A Method for Single Particle Mass Spectrometry of Ice Nuclei, Aerosol Sci. Technol., 37, 460-470, doi:10.1080/02786820300976, 2003.

Cziczo, D. J., DeMott, P. J., Brooks, S. D., Prenni, A. J., Thomson, D. S., Baumgardner, D., Wilson, J. C., Kreidenweis, S. M., and Murphy, D. M.: Observations of organic species and atmospheric ice formation, Geophys. Res. Lett., 31, L12116, doi:10.1029/2004g1019822, 2004.

Cziczo, D. J., Froyd, K. D., Gallavardin, S. J., Möhler, O., Benz, S., Saathoff, H., and Murphy, D. M.: Deactivation of ice nuclei due to atmospherically relevant surface coatings, Environ. Res. Lett., 4, 044013, doi:10.1088/1748-9326/4/4/044013, 2009a.

Cziczo, D. J., Stetzer, O., Worringen, A., Ebert, M., Weinbruch, S., Kamphus, M., Gallavardin, S. J., Curtius, J., Borrmann, S., Froyd, K. D., Mertes, S., Möhler, O., and Lohmann, U.: Inadvertent climate modification due to anthropogenic lead, Nat. Geosci., 2, 333-336, doi:10.1038/ngeo499, 2009b.

DeMott, P. J., Cziczo, D. J., Prenni, A. J., Murphy, D. M., Kreidenweis, S. M., Thomson, D. S., Borys, R., and Rogers, D. C.: Measurements of the concentration and composition of nuclei for cirrus formation, P. Natl. Acad. Sci. USA, 100, 14655-14660, doi:10.1073/pnas.2532677100, 2003.

Draxler, R. R. and Rolph, G. D.: HYSPLIT (HYbrid Single-Particle Lagrangian Integrated Trajectory) Model access via NOAA ARL READY Website, available at: http://www.arl.noaa.gov/ HYSPLIT.php, last access: 25 November 2014.

Ebert, M., Worringen, A., Benker, N., Mertes, S., Weingartner, E., and Weinbruch, S.: Chemical composition and mixing-state of ice residuals sampled within mixed phase clouds, Atmos. Chem. Phys., 11, 2805-2816, doi:10.5194/acp-11-2805-2011, 2011.

Flato, G., Marotzke, J., Abiodun, B., Braconnot, P., Chou, S. C., Collins, W., Cox, P., Driouech, F., Emori, S., Eyring, V., Forest, C., Gleckler, P., Guilyardi, E., Jakob, C., Kattsov, V., C., R., and Rummukainen, M.: Evaluation of Climate Models, in: Climate Change 2013: The Physical Science Basis. Contribution of Working Group I to the Fifth Assessment Report of the Intergovernmental Panel on Climate Change, edited by: Stocker, T. F., Qin, D., Plattner, G.-K., Tignor, M., Allen, S. K., Boschung, J., Nauels, A., Xia, Y., Bex, V., and Midgley, P. M., Cambridge University Press, Cambridge, United Kingdom and New York, NY, USA., 741-866, 2013.

Gorbunov, B., Baklanov, A., Kakutkina, N., Windsor, H. L., and Toumi, R.: Ice nucleation on soot particles, J. Aerosol Sci., 32, 199-215, doi:10.1016/S0021-8502(00)00077-X, 2001.

Hiranuma, N., Brooks, S. D., Moffet, R. C., Glen, A., Laskin, A., Gilles, M. K., Liu, P., Macdonald, A. M., Strapp, J. W., and McFarquhar, G. M.: Chemical characterization of individual parti- cles and residuals of cloud droplets and ice crystals collected on board research aircraft in the ISDAC 2008 study, J. Geophys. Res., 118, 6564-6579, doi:10.1002/jgrd.50484, 2013.

Hoose, C. and Möhler, O.: Heterogeneous ice nucleation on atmospheric aerosols: a review of results from laboratory experiments, Atmos. Chem. Phys., 12, 9817-9854, doi:10.5194/acp-12-98172012, 2012.

Hu, Y.-X., Yang, P., Lin, B., Gibson, G., and Hostetler, C.: Discriminating between spherical and non-spherical scatterers with lidar using circular polarization: a theoretical study, J. Quant. Spectrosc. Ra., 79-80, 757-764, doi:10.1016/S0022-4073(02)003205, 2003.

Kamphus, M., Ettner-Mahl, M., Klimach, T., Drewnick, F., Keller, L., Cziczo, D. J., Mertes, S., Borrmann, S., and Curtius, J.: Chemical composition of ambient aerosol, ice residues and cloud droplet residues in mixed-phase clouds: single particle analysis during the Cloud and Aerosol Characterization Experiment (CLACE 6), Atmos. Chem. Phys., 10, 8077-8095, doi:10.5194/acp-10-8077-2010, 2010.

Kandler, K., Benker, N., Bundke, U., Cuevas, E., Ebert, M., Knippertz, P., Rodríguez, S., Schütz, L., and Weinbruch, S.: Chemical composition and complex refractive index of Saharan Mineral Dust at Izaña, Tenerife (Spain) derived by electron microscopy, Atmos. Environ., 41, 8058-8074, doi:10.1016/j.atmosenv.2007.06.047, 2007.

Kandler, K., Schütz, L., Deutscher, C., Hofmann, H., Jäckel, S., Knippertz, P., Lieke, K., Massling, A., Schladitz, A., Weinzierl, B., Zorn, S., Ebert, M., Jaenicke, R., Petzold, A., and Weinbruch, S.: Size distribution, mass concentration, chemical and mineralogical composition, and derived optical parameters of the boundary layer aerosol at Tinfou, Morocco, during SAMUM 2006, Tellus, 61B, 32-50, doi:10.1111/j.16000889.2008.00385.x, 2009.

Kandler, K., Schütz, L., Jäckel, S., Lieke, K., Emmel, C., MüllerEbert, D., Ebert, M., Scheuvens, D., Schladitz, A., Šegvić, B., Wiedensohler, A., and Weinbruch, S.: Ground-based offline aerosol measurements at Praia, Cape Verde, during the Saharan Mineral Dust Experiment: Microphysical properties and mineralogy, Tellus, 63B, 459-474, doi:10.1111/j.16000889.2011.00546.x, 2011.

Klein, H., Haunold, W., Bundke, U., Nillius, B., Wetter, T., Schallenberg, S., and Bingemer, H.: A new method for sampling of atmospheric ice nuclei with subsequent analysis in a static diffusion chamber, Atmos. Res., 96, 218-224, doi:10.1016/j.atmosres.2009.08.002, 2010.

Knopf, D. A., Wang, B., Laskin, A., Moffet, R. C., and Gilles, M. K.: Heterogeneous nucleation of ice on anthropogenic organic particles collected in Mexico City, Geophys. Res. Lett., 37, L11803, doi:10.1029/2010g1043362, 2010.

Knopf, D. A., Alpert, P. A., Wang, B., O’Brien, R. E., Kelly, S. T., Laskin, A., Gilles, M. K., and Moffet, R. C.: Microspectroscopic imaging and characterization of individually identified ice nucleating particles from a case field study, J. Geophys. Res., 119, 10365-10381, doi:10.1002/2014jd021866, 2014.

Koehler, K. A., DeMott, P. J., Kreidenweis, S. M., Popovicheva, O. B., Petters, M. D., Carrico, C. M., Kireeva, E. D., Khokhlova, T. D., and Shonija, N. K.: Cloud condensation nuclei and ice nucleation activity of hydrophobic and hy- 
drophilic soot particles, Phys. Chem. Chem. Phys., 11, 79067920, doi:10.1039/b905334b, 2009.

Kupiszewski, P., Weingartner, E., Vochezer, P., Bigi, A., Rosati, B., Gysel, M., Schnaiter, M., and Baltensperger, U.: The Ice Selective Inlet: a novel technique for exclusive extraction of pristine ice crystals in mixed-phase clouds, Atmos. Meas. Tech. Discuss., 7, 12481-12515, doi:10.5194/amtd-7-12481-2014, 2014.

Lohmann, U. and Feichter, J.: Global indirect aerosol effects: a review, Atmos. Chem. Phys., 5, 715-737, doi:10.5194/acp-5-7152005, 2005.

Mertes, S., Galgon, D., Schwirn, K., Nowak, A., Lehmann, K., Massling, A., Wiedensohler, A., and Wieprecht, W.: Evolution of particle concentration and size distribution observed upwind, inside and downwind hill cap clouds at connected flow conditions during FEBUKO, Atmos. Environ., 39, 4233-4245, doi10.1016/j.atmosenv.2005.02.009, 2005a.

Mertes, S., Lehmann, K., Nowak, A., Massling, A., and Wiedensohler, A.: Link between aerosol hygroscopic growth and droplet activation observed for hill-capped clouds at connected flow conditions during FEBUKO, Atmos. Environ., 39, 4247-4256, doi:10.1016/j.atmosenv.2005.02.010, 2005b.

Mertes, S., Verheggen, B., Walter, S., Connolly, P., Ebert, M., Schneider, J., Bower, K. N., Cozic, J., Weinbruch, S., Baltensperger, U., and Weingartner, E.: Counterflow Virtual Impactor Based Collection of Small Ice Particles in Mixed-Phase Clouds for the Physico-Chemical Characterization of Tropospheric Ice Nuclei: Sampler Description and First Case Study, Aerosol Sci. Technol., 41, 848-864, doi:10.1080/02786820701501881, 2007.

Murray, B. J., O'Sullivan, D., Atkinson, J. D., and Webb, M. E.: Ice nucleation by particles immersed in supercooled cloud droplets, Chem. Soc. Rev., 41, 6519-6554, doi:10.1039/c2cs35200a, 2012.

Petzold, A., Ogren, J. A., Fiebig, M., Laj, P., Li, S.-M., Baltensperger, U., Holzer-Popp, T., Kinne, S., Pappalardo, G., Sugimoto, N., Wehrli, C., Wiedensohler, A., and Zhang, X.-Y.: Recommendations for reporting "black carbon" measurements, Atmos. Chem. Phys., 13, 8365-8379, doi:10.5194/acp-13-83652013, 2013.

Prenni, A. J., Demott, P. J., Rogers, D. C., Kreidenweis, S. M., McFarquhar, G. M., Zhang, G., and Poellot, M. R.: Ice nuclei characteristics from M-PACE and their relation to ice formation in clouds, Tellus B, 61, 436-448, doi:10.1111/j.16000889.2009.00415.x, 2009a.

Prenni, A. J., Petters, M. D., Faulhaber, A., Carrico, C. M., Ziemann, P. J., Kreidenweis, S. M., and DeMott, P. J.: Heterogeneous ice nucleation measurements of secondary organic aerosol generated from ozonolysis of alkenes, Geophys. Res. Lett., 36, L06808, doi:10.1029/2008g1036957, 2009b.

Prenni, A. J., Petters, M. D., Kreidenweis, S. M., Heald, C. L., Martin, S. T., Artaxo, P., Garland, R. M., Wollny, A. G., and Pöschl, U.: Relative roles of biogenic emissions and Saharan dust as ice nuclei in the Amazon basin, Nat. Geosci., 2, 402-405, doi:10.1038/ngeo517, 2009c.

Pruppacher, H. R. and Klett, J. D.: Microphysics of clouds and precipitation, 2 ed., Kluwer Academic Publishers, Dordrecht, 1997.

R core team: R: A language and environment for statistical computing, available at: http://www.R-project.org/, last access: 31 October 2014.
Richardson, M. S., DeMott, P. J., Kreidenweis, S. M., Cziczo, D. J., Dunlea, E. J., Jimenez, J. L., Thomson, D. S., Ashbaugh, L. L., Borys, R. D., Westphal, D. L., Casuccio, G. S., and Lersch, T. L.: Measurements of heterogeneous ice nuclei in the western United States in springtime and their relation to aerosol characteristics, J. Geophys. Res., 112, D02209, doi:10.1029/2006jd007500, 2007.

Santachiara, G., Di Matteo, L., Prodi, F., and Belosi, F.: Atmospheric particles acting as Ice Forming Nuclei in different size ranges, Atmos. Res., 96, 266-272, doi:10.1016/j.atmosres.2009.08.004, 2010.

Schenk, L. P., Mertes, S., Kästner, U., Frank, F., Nillius, B., Bundke, U., Rose, D., Schmidt, S., Schneider, J., Worringen, A., Kandler, K., Bukowiecki, N., Ebert, M., Curtius, J., and Stratmann, F.: Characterization and first results of an ice nucleating particle measurement system based on counterflow virtual impactor technique, Atmos. Meas. Tech. Discuss., 7, 10585-10617, doi:10.5194/amtd-7-10585-2014, 2014.

Schill, G. P. and Tolbert, M. A.: Heterogeneous Ice Nucleation on Simulated Sea-Spray Aerosol Using Raman Microscopy, J. Phys. Chem. C, 118, 29234-29241, doi:10.1021/jp505379j, 2014.

Schmidt, S., Schneider, J., Klimach, T., Mertes, S., Schenk, L. P., Curtius, J., Kupiszewski, P., Hammer, E., Vochezer, P., Lloyd, G., Ebert, M., Kandler, K., Weinbruch, S., and Borrmann, S.: In-situ single submicron particle composition analysis of ice residuals from mountain-top mixed-phase clouds in Central Europe, Atmos. Chem. Phys. Discuss., 15, 4677-4724, doi:10.5194/acpd15-4677-2015, 2015.

Sullivan, R. C., Miñambres, L., DeMott, P. J., Prenni, A. J., Carrico, C. M., Levin, E. J. T., and Kreidenweis, S. M.: Chemical processing does not always impair heterogeneous ice nucleation of mineral dust particles, Geophys. Res. Lett., 37, L24805, doi:10.1029/2010g1045540, 2010.

Targino, A. C., Krejci, R., Noone, K. J., and Glantz, P.: Single particle analysis of ice crystal residuals observed in orographic wave clouds over Scandinavia during INTACC experiment, Atmos. Chem. Phys., 6, 1977-1990, doi:10.5194/acp-6-1977-2006, 2006.

Twohy, C. H. and Poellot, M. R.: Chemical characteristics of ice residual nuclei in anvil cirrus clouds: evidence for homogeneous and heterogeneous ice formation, Atmos. Chem. Phys., 5, 22892297, doi:10.5194/acp-5-2289-2005, 2005.

WDCA: Global Atmosphere Watch World Data Centre for Aerosol, available at: http://www.gaw-wdca.org, last access via http:// ebas.nilu.no/: 19 March 2014.

Weingartner, E., Nyeki, S., and Baltensperger, U.: Seasonal and diurnal variation of aerosol size distributions $(10<\mathrm{D}<750 \mathrm{~nm})$ at a high-alpine site (Jungfraujoch $3580 \mathrm{~m}$ a.s.1.), J. Geophys. Res., 104, 26809-26820, doi:10.1029/1999JD900170, 1999.

Wex, H., DeMott, P. J., Tobo, Y., Hartmann, S., Rösch, M., Clauss, T., Tomsche, L., Niedermeier, D., and Stratmann, F.: Kaolinite particles as ice nuclei: learning from the use of different kaolinite samples and different coatings, Atmos. Chem. Phys., 14, 5529_ 5546, doi:10.5194/acp-14-5529-2014, 2014.

Wise, M. E., Baustian, K. J., Koop, T., Freedman, M. A., Jensen, E. J., and Tolbert, M. A.: Depositional ice nucleation onto crystalline hydrated $\mathrm{NaCl}$ particles: a new mechanism for ice formation in the troposphere, Atmos. Chem. Phys., 12, 1121-1134, doi:10.5194/acp-12-1121-2012, 2012. 
Yakobi-Hancock, J. D., Ladino, L. A., and Abbatt, J. P. D.: Feldspar minerals as efficient deposition ice nuclei, Atmos. Chem. Phys., 13, 11175-11185, doi:10.5194/acp-13-11175-2013, 2013.

Zimmermann, F., Weinbruch, S., Schütz, L., Hofmann, H., Ebert, M., Kandler, K., and Worringen, A.: Ice nucleation properties of the most abundant mineral dust phases, J. Geophys. Res., 113, D23204, doi:10.1029/2008JD010655, 2008.
Zuberi, B., Bertram, A. K., Koop, T., Molina, L. T., and Molina, M. J.: Heterogeneous Freezing of Aqueous Particles Induced by Crystallized $\left(\mathrm{NH}_{4}\right)_{2} \mathrm{SO}_{4}$, Ice, and Letovicite, Phys. Chem. A., 105, 6458-6464, doi:10.1021/jp010094e, 2001.

Zuberi, B., Bertram, A. K., Cassa, C. A., Molina, L. T., and Molina, M. J.: Heterogeneous nucleation of ice in $\left(\mathrm{NH}_{4}\right)_{2} \mathrm{SO}_{4}-\mathrm{H}_{2} \mathrm{O}$ particles with mineral dust immersions, Geophys. Res. Lett., 29, 142-1-142-4, doi:10.1029/2001g1014289, 2002. 